\title{
The evolution of mode- 2 nonlinear internal waves over the northern Heng-Chun Ridge south of Taiwan
}

\author{
S. R. Ramp ${ }^{1}$, Y. J. Yang ${ }^{2}$, D. B. Reeder ${ }^{3}$, M. C. Buijsman ${ }^{4}$, and F. L. Bahr ${ }^{5}$ \\ ${ }^{1}$ Soliton Ocean Services, Inc., Carmel Valley, CA 93924, USA \\ ${ }^{2}$ Institute of Oceanography, National Taiwan University, Taipei, Taiwan \\ ${ }^{3}$ Department of Oceanography, Naval Postgraduate School, Monterey, CA 93943, USA \\ ${ }^{4}$ University of Southern Mississippi, Stennis Space Center, MS 39529, USA \\ ${ }^{5}$ Monterey Bay Aquarium Research Institute, Moss Landing, CA 95039, USA \\ Correspondence to: S. R. Ramp (sramp@solitonocean.com)
}

Received: 20 November 2014 - Published in Nonlin. Processes Geophys. Discuss.: 18 February 2015

Revised: 2 June 2015 - Accepted: 12 June 2015 - Published: 27 July 2015

\begin{abstract}
Two research cruises were conducted from the R/V OCEAN RESEARCHER 3 during 05-16 August 2011 to study the generation and propagation of high-frequency nonlinear internal waves (NLIWs) over the northern HengChun Ridge south of Taiwan. The primary study site was on top of a smaller ridge about $15 \mathrm{~km}$ wide by $400 \mathrm{~m}$ high atop the primary ridge, with a sill depth of approximately $600 \mathrm{~m}$. A single mooring was used in conjunction with shipboard observations to sample the temperature, salinity and velocity structure over the ridge. All the sensors observed a profusion of mode-2 NLIWs. Some of the waves were solitary, while others had as many as seven evenly spaced waves per packet. The waves all exhibited classic mode- 2 velocity structure with a core near 150-200 m and opposing velocities in the layers above and below. At least two and possibly three most common propagation directions emerged from the analysis, suggesting multiple generation sites near the eastern side of the ridge. The turbulent dissipation due to overturns in the wave cores was very high at order $10^{-4}-10^{-3} \mathrm{~W} \mathrm{~kg}^{-1}$. The energy budget suggests that the waves cannot persist very far from the ridge and likely do not contribute to the South China Sea transbasin wave phenomenon.
\end{abstract}

\section{Introduction}

Since 1999, a series of joint programs between Taiwan and the United States have been studying the world's largest high-frequency nonlinear internal waves (NLIWs) in the northeastern South China Sea. These waves originate in the vicinity of the Luzon Strait between Taiwan and the Philippines, and propagate WNW across the deep basin toward the Chinese continental shelf and slope. Earlier programs focused on a basic description of the wave properties including their amplitude, orbital velocities, and wave celerity (Duda et al., 2004; Liu et al., 2004; Ramp et al., 2004, 2010; Yang et al., 2004; Lien et al., 2005; Klymak et al., 2006; Alford et al., 2010). More recently, the US Office of Naval Research (ONR) and Taiwan National Science Council (NSC) jointly sponsored the Internal Waves in Straits Experiment (IWISE) to focus on the wave generation physics, thereby improving predictive skill for wave arrivals in the far field.

It is now generally accepted that the internal tide is formed by the flux of the barotropic tide in a stratified fluid across abrupt topography. The initial pycnocline depressions that propagate away from the topography can form either as lee waves on the ebb tide (Maxworthy, 1979; Farmer and Smith, 1980; Apel et al., 1985) or as a downward surge off topography on the flood tide (Lee and Beardsley, 1974; Scotti et al., 2007; Lai et al., 2010). What happens next depends on the strength of the forcing, the slope of the wave ray path relative to the topography, and the tidal excursion. It has now been demonstrated that relatively weak forcing over wide topogra- 
phy and shallow slopes favors the formation of tidal beams, while stronger forcing over steep, supercritical topography favors lee waves, higher modes, wave breaking, and mixing (Garrett and Kunze, 2007; Legg and Klymak, 2008; Klymak et al., 2010, 2012; Pinkel et al., 2012). All these outcomes can lead to high-frequency nonlinear internal waves (NLIW), either by trapping energy in the upper layer or by nonlinear steepening of the internal tide in the presence of nonhydrostatic effects and rotational dispersion (Farmer et al., 2009; $\mathrm{Li}$ and Farmer, 2011; Buijsman et al., 2010a; Zhang et al., 2011).

Several complicating factors make the situation in the Luzon Strait particularly interesting and challenging. The first is the presence of two ridges, the eastern (Lan-yu) ridge and the western (Heng-Chun) ridge, both of which are capable of generating internal tides. Both the ridge separation distance and their relative heights are functions of latitude, such that the two ridges are in resonance with respect to the semidiurnal internal tide at certain locations (Farmer et al., 2009; Buijsman et al., 2010a, b, 2012; Zhang et al., 2011; Li and Farmer, 2011; Alford et al., 2011). Resonance in this usage means that the western ridge lies exactly one surface bounce downstream for an internal wave beam, such that westwardpropagating waves generated at the western ridge reinforce waves incoming from the eastern ridge. Destructive interference can also occur when eastward-propagating waves from the western ridge meet head-on with westward propagating waves from the eastern ridge. In this case, standing waves can result in the deep basin between the ridges, leading to a southward energy flux normal to the waves (Alford et al., 2011).

A second complicating factor is that the generation problem is highly three-dimensional. A multitude of different bottom slopes in the strait favor diurnal internal tide generation at some locations and semidiurnal at others (Zhang et al., 2011; Alford et al., 2011). This admits the possibility that the far-field nonlinear internal wave fronts actually represent a combination of waves emerging from several sources, many of which have likely not been identified. The straightness of the wave fronts supports this idea, since wave fronts emerging from a point source would be spherical (Vlasenko et al., 2010; Zhang et al., 2011). Harmonic analysis indicates that the diurnal tide is stronger in the Luzon Strait than the semidiurnal, but the diurnal tide is clearly not resonant anywhere with the second ridge, and is subject to stronger rotational dispersion, meaning that downstream of the western ridge, the semidiurnal component dominates the response ( $\mathrm{Li}$ and Farmer, 2011).

The third complicating factor is the complexity of the barotropic tide itself. A large fortnightly envelope surrounds the barotropic tidal currents. Near spring tide the tidal currents exceed $1.5 \mathrm{~m} \mathrm{~s}^{-1}$ while at neap tide they are less than $0.5 \mathrm{~m} \mathrm{~s}^{-1}$ (Ramp et al., 2010). The tide has a strong diurnal inequality and is mostly diurnal at spring tide but semidiurnal at neap. Furthermore, the tide in the Luzon strait is asym- metric with much stronger currents on ebb (towards the $\mathrm{Pa}$ cific) than on flood (towards the SCS). The result is that the strongest tide by far is the stronger of the two ebb tides. These processes introduce a high degree of temporal variability to the generation problem.

To attack these problems, the Nonlinear Internal Waves Initiative (NLIWI) program made dense field observations during 2010-2011 at several sites around the Luzon Strait in addition to the $20.5^{\circ} \mathrm{N}$ axis most frequently sampled by previous investigators. One of these sites was over the HengChun (HC) Ridge near $21^{\circ} 34^{\prime} \mathrm{N}, 120^{\circ} 54^{\prime} \mathrm{E}$, about $35 \mathrm{~km}$ south of Taiwan. The site sits on a sub-ridge about $15 \mathrm{~km}$ wide by $400 \mathrm{~m}$ high atop the primary ridge. These sub-ridges all have supercritical bottom slopes and contribute strongly to the lee wave formation and tidal dissipation processes (Buijsman et al., 2012). The site was first visited during the IWISE Pilot Study during June 2010 (Ramp et al., 2012; hereafter RYRB12). They observed a clear convex-type mode-2 NLIW atop the ridge with a westward-propagating core centered near $100 \mathrm{~m}$ depth. Convex waves arise in a three-layer system when the middle layer is relatively thin (less than onehalf the water depth) and consist of an upward displacement of the thermal structure in the upper water column and the opposite below. This results in a "bulge" in the thermocline with velocity in the same direction that the wave is traveling (Yang et al., 2009, 2010). The RYRB12 observations were consistent with the lee wave generation mechanism by a tidal flow that was supercritical with respect to mode-2 internal waves but not mode- 1 . The results clearly suggested that the ocean's behavior at the northern $\mathrm{HC}$ ridge site was different from the Batan/Itbayat Island passage on the eastern ridge, and merited a second visit.

The August 2011 field program added a single mooring atop the ridge in addition to several ship-based time series stations and continuous underway sampling (Fig. 1). The program was intended to assess the robustness of the pilot study results, allow comparison to numerical models, and determine the site's contribution, if any, to the far-field internal waves and tides observed to the west in the South China Sea. Towards this end the energy balance for the waves is assessed to estimate the likely lifetime and propagation distance of the waves. The data and methods are outlined in Sect. 2, followed by the results in Sect. 3. The discussion includes the wave energetics, comparisons with the MITgcm model (Marshall et al., 1997; Buijsman et al., 2012) runs for the same location, and a discussion of the likely wave dynamics. The summary and conclusions appear in Sect. 5.

\section{Data and methods}

The cruise was divided into two legs on the R/V OCEAN RESEARCHER 3 operated by the National Sun Yat-sen University in Kaohsiung, Taiwan. The first leg from 5 to $9 \mathrm{Au}-$ gust 2011 was spent primarily recovering gear from a related 

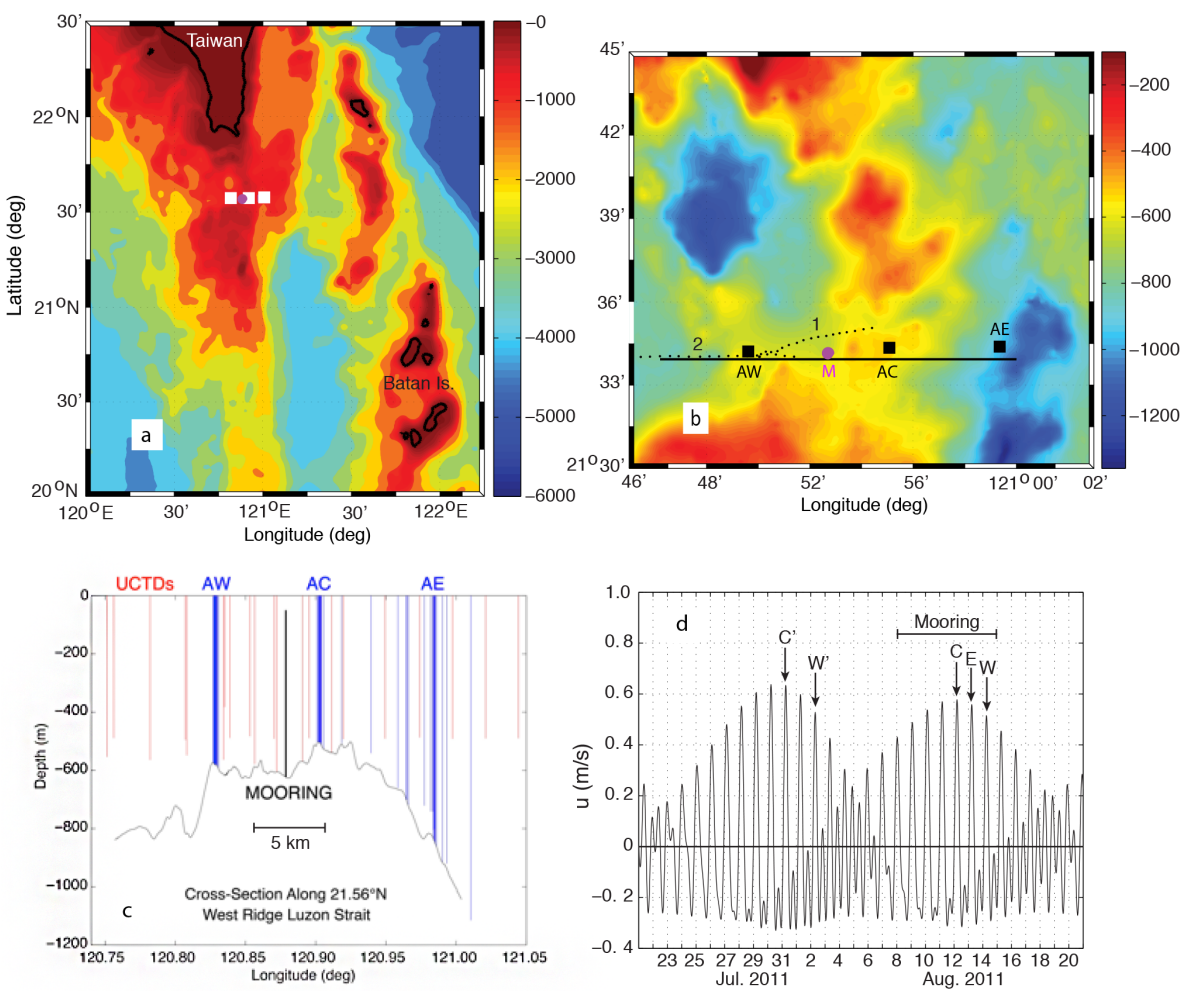

Figure 1. (a) Locator map showing the experiment site south of Taiwan; (b) a zoomed-in version of the plan view showing the local topography. Black squares indicate the $24 \mathrm{~h}$ time series stations and the magenta dot is the mooring location. The small black dots indicate the UCTD stations along the two transects numbered 1 and 2. (c) A cross-sectional view of the transect shown by the black line in (b). In both panels, the letters AW, AC, and AE indicate the locations of the $24 \mathrm{~h}$ time series stations Anchor West, Anchor Center, and Anchor East, respectively. (d) The timing of the anchor stations with respect to the TPXO7.2 fortnightly tidal envelope. The letters $\mathrm{C}^{\prime}$ and $\mathrm{W}^{\prime}$ indicate times analogous to $\mathrm{C}$ and $\mathrm{W}$ where model output was extracted for comparison.

project in the deep Pacific, then deploying the mooring on top of the $\mathrm{HC}$ ridge at $21^{\circ} 34.1^{\prime} \mathrm{N}, 120^{\circ} 52.7^{\prime} \mathrm{E}, 609 \mathrm{~m}$ depth (Fig. 1). This location was near the center of the ridge top, in a channel with slightly shallower water to the east than the west (Fig. 1b, c). A high (shallow) spot just east of the mooring divided the channel into two branches, one tending in from the northeast and the other from the southeast (Fig. 1b). The sill depth in both channels was similar, around $580 \mathrm{~m}$ near the eastern end. The channel opened up at the western end and was less restricted meridionally. The bottom slope at both ends of the channel was quite steep (Fig. 1c), supercritical to both the diurnal and semidiurnal tides. The cruise timing was chosen to span the spring tide, as predicted by both the Oregon State TOPEX/Poseidon Global Inverse Solution (TPXO) (Egbert and Erofeeva, 2002; Egbert et al., 1994) and by combining tidal constituents for the region calculated using long time series from earlier experiments (Ramp et al., 2010). The tide was nearly diurnal during this time (Fig. 1d).

The mooring was in the water from 08:30 GMT (Greenwich Mean Time) 8 August to 09:30 15 August and all the instruments worked well. Two acoustic Doppler current profilers (ADCPs) were used to measure velocity: a $150 \mathrm{kHz}$ unit was mounted in a syntactic foam sphere at $200 \mathrm{~m}$ depth "looking" upward, and a $300 \mathrm{kHz}$ unit was moored in a stainless steel cage at $420 \mathrm{~m}$ "looking" downward. The $150 \mathrm{kHz}$ unit sampled in $8 \mathrm{~m}$ bins and the $300 \mathrm{kHz}$ unit used $4 \mathrm{~m}$ bins. Both instruments pinged continuously once every $10 \mathrm{~s}$ and the data were averaged to $1 \mathrm{~min}$ intervals in post-processing. Temperature was sensed at 1 min intervals using SBE39 TP recorders and SBE56 for T only. The lightweight SBE56 instruments were suspended on a pennant flown above the syntactic foam sphere in order to lie within the sampling range of the ADCP. A few SBE39s were also deployed on this line to compute the positions of the instruments in the water column. The nominal positions of the instruments were 50, $125,200,300,400$, and $610 \mathrm{~m}$ for the SBE39s and 70, 90, $110,145,165$, and $185 \mathrm{~m}$ for the SBE56s. Mooring blowdown was a severe problem in the extremely high currents atop the ridge. The ADCPs quit working when the vector currents exceeded about $1.25 \mathrm{~m} \mathrm{~s}^{-1}$, which apparently corresponded to an instrument tilt exceeding 25 degrees. The instrument blow-down exceeded $100 \mathrm{~m}$ vertically during these times. This happened once per day for $2-4 \mathrm{~h}$ on the stronger ebb tide. The instruments otherwise operated from near their designed depths. The large vertical excursions required all the data to be re-mapped to a constant depth/time grid be- 
fore further analysis could be accomplished. Isopycnal displacements, APE, etc. were computed as displacements from mean levels in the depth-time grid.

Leg II during 11-16 August 2012 was dedicated primarily to sampling an across-sill transect and three $24 \mathrm{~h}$ time series stations using the conductivity-temperaturedepth (CTD) and lowered ADCP (LADCP) package from the OR3. The LADCP was configured as two Teledyne RDI $300 \mathrm{kHz}$ broadband units with a downward-looking master and upward-looking slave. The LADCP data were processed using the velocity inversion method with bottom tracking (Visbeck, 2002; Thurnherr, 2010). The algorithms are publicly available from a web site at IFM-GEOMAR at the University of Kiel, Germany. The time required to collect each profile was naturally a function of bottom depth. For example, at $600 \mathrm{~m}$ depth, each profile took roughly $38 \mathrm{~min}$ to complete and both down- and up-casts were used. The sampling rate was adequate to resolve internal tides, lee waves, and bores, but inadequate to sample high-frequency nonlinear internal waves. The transect was occupied first and consisted of five stations steaming off the ridge towards the east from 622 to $2441 \mathrm{~m}$ depth. The center $(538 \mathrm{~m})$, eastern $(950 \mathrm{~m})$ and western $(610 \mathrm{~m})$ time series were then occupied on 12 , 13, and 14 August, respectively (Fig. 1b, c).

On 15 August, the mooring was recovered first, followed by two short underway CTD (UCTD) sections before the ship steamed back to Kaohsiung. The UCTD is a free-falling CTD probe that can be deployed and retrieved while the vessel is underway at up to 10 knots (Rudnick and Klinke, 2007). The thin Spectra line spools off from both a deck-mounted reel, which lays line out along the sea surface, and from the tail of the probe, which allows the probe to fall straight down. The probe is then retrieved by hauling back on the reel. For this application, profiles were collected to $500 \mathrm{~m}$ with the vessel steaming at four knots. Following each cast, the data were downloaded to a PC via Bluetooth while the probe tail was rewound in preparation for the next cast. The entire cycle could be reliably accomplished in about $20 \mathrm{~min}$, resulting in profiles nominally every $2.5 \mathrm{~km}$.

Several important underway data sets were collected throughout the cruise. The ship's hull-mounted ADCP, a Teledyne RDI $150 \mathrm{kHz}$ Ocean Surveyor unit with a basic averaging interval of $5 \mathrm{~min}$, sampled to nominally $500 \mathrm{~m}$ depth. Acoustic backscatter data at 38 and $120 \mathrm{kHz}$ were collected continuously using a Simrad EK500 echo sounder sampling at $2 \mathrm{~Hz}$. Finally, the ship's radar returns were digitally recorded once per minute. These images proved invaluable in tracking the orientation, propagation speed, and propagation direction of the surface roughness fronts associated with the strong nonlinear internal waves.

\section{Results}

\subsection{Anchor stations}

The results from RYRB12 suggested that westwardpropagating higher-mode internal tides and NLIW are generated at the site via lee waves forming east of the ridge on the stronger ebb tide. The transect and station Anchor East (AE) were designed to look for these structures on the eastern side of the ridge (Fig. 2). The transect (left panels) was occupied during a westward tide (blue shades) that also had a southward component (Fig. 2c, d). The tide was clearly bottomtrapped in the form of a tidal bore as described by Buijsman et al. (2012) and was in the process of surging up over the top of the ridge. The surge elevated the deep isotherms by $75-100 \mathrm{~m}$ as it moved westward (Fig. 2a). The timing of the transect was unfortunately not conducive to observing isotherm depressions following the strong ebb (eastward) tide. The Kuroshio Current was evident as the salinity maximum near $100 \mathrm{~m}$ depth over the eastern flank of the ridge.

Station AE was occupied for $24 \mathrm{~h}$ during 13 August (note the $x$ axis change from space to time, Fig. 2 right panels). The station was located in nominally $1000 \mathrm{~m}$ of water about $9.5 \mathrm{~km}$ back (east) from the sill. The isotherms (Fig. 2e) did not at any time show anything that resembled a lee wave. The ebb tide had already separated from the bottom (Fig. 2g, h). These results combined with the MITgcm model runs (discussed later) suggest the station may have been located too far east to observe the most turbulent portion of the flow over the ridge. The salinity maximum was more or less present depending on the eastward (less) or westward (more) phase of the tide (Fig. 2f). Nothing resembling a mode-2 structure was observed in either the transect or station $\mathrm{AE}$.

Stations Anchor Center (AC) and Anchor West (AW) were located to observe mode-2 structures on top of the ridge (Fig. 1), and together with the mooring station (M), to determine their speed and direction of propagation. Station AC was located $2.8 \mathrm{~km}$ east of station $\mathrm{M}$, which was in turn located $5.9 \mathrm{~km}$ east of station AW (Fig. 1b, c). Based on the propagation speed of $0.85 \mathrm{~m} \mathrm{~s}^{-1}$ estimated by RYRB12, it would take about $1 \mathrm{~h}$ for the expected structures to travel from $\mathrm{AC}$ to $\mathrm{M}$, and $2 \mathrm{~h}$ from $\mathrm{M}$ to $\mathrm{AW}$. Note that since stations $\mathrm{AC}$ and $\mathrm{AW}$ were sampled 2 days apart, no coherence is expected between these two stations.

Station AC featured a strong bulge in the thermal structure centered near $200 \mathrm{~m}$ from 05:20 to 13:30 on August 12 (Fig. 3e). The bulge created a lens of $17^{\circ} \mathrm{C}$ water roughly $100 \mathrm{~m}$ thick which was reminiscent of the mode- 2 feature(s) observed during June 2010. The thermal bulge overlapped with the peak ebb tide which occupied the lower $200 \mathrm{~m}$ of the water column, and had a corresponding velocity signature: The thermal feature was associated with a minimum in the eastward velocity from 05:20 to 08:20 and westward velocity from 08:20 to 13:30. The bulge was asymmetric in shape: The first upward displacement arrived at 06:00, earlier 

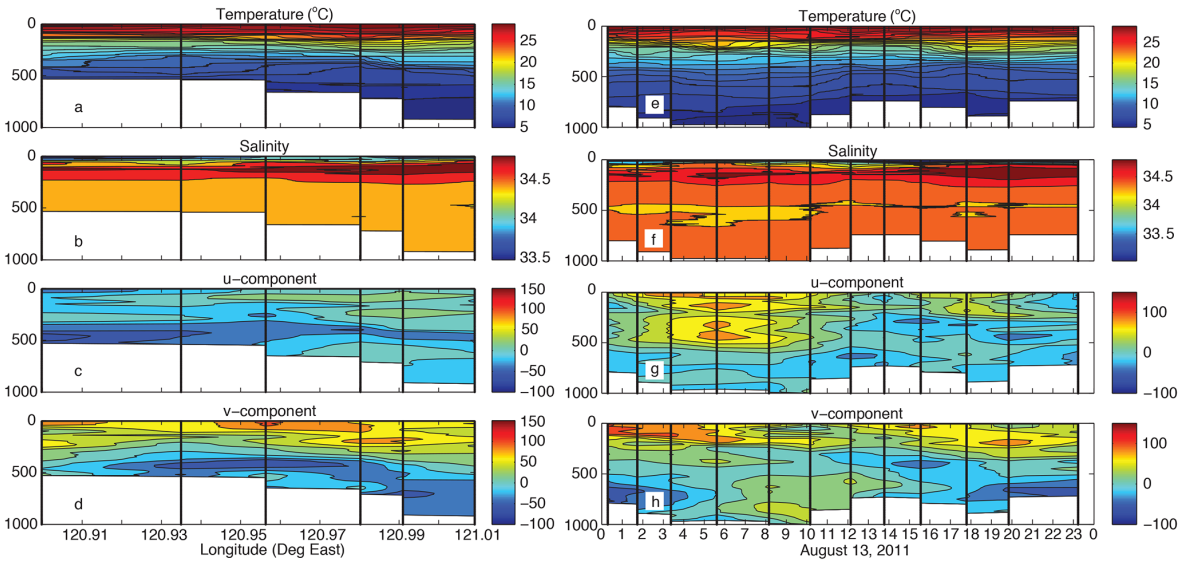

Figure 2. CTD and LADCP data for a zonal section along $21^{\circ} 34.1^{\prime} \mathrm{N}$ (left panels) and the time-series station $\mathrm{AE}$ at $21^{\circ} 34.1^{\prime} \mathrm{N}, 120^{\circ} 59.1^{\prime} \mathrm{E}$ (right panels). The vertical solid lines represent the times and locations of the individual CTD/LADCP casts.
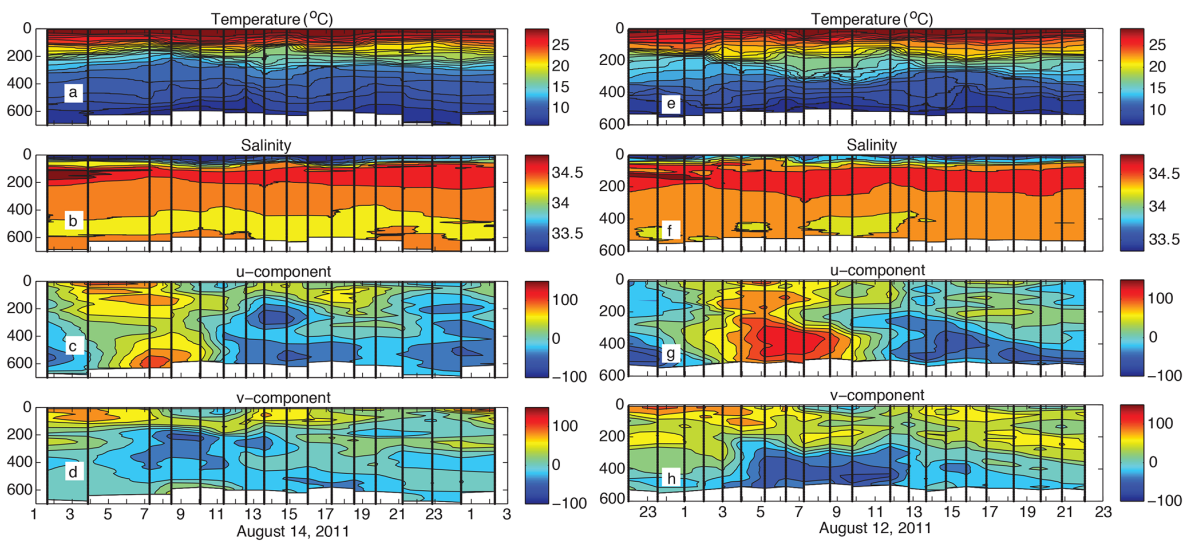

Figure 3. CTD and LADCP data for stations AW (left panels) and AC (right panels) at $21^{\circ} 34.1^{\prime} \mathrm{N}, 120^{\circ} 49.7^{\prime} \mathrm{E}$ and $21^{\circ} 34.1^{\prime} \mathrm{N}$, $120^{\circ} 54.1^{\prime} \mathrm{E}$, respectively. The vertical solid lines represent the times of the individual CTD/LADCP casts.

than the maximum downward displacement at 07:20. This was likely due to the background shear due to the strong, bottom-trapped ebb tide during this time (Fig. 3g). The second maximum upward displacement at 11:40 arrived well after the maximum downward displacement at 10:00. By this time the tide had reversed and was westward in the lower portion of the water column. Given the profile spacing, it cannot be determined from this data set if these features represent an internal tide or aliased NLIW-like features. This will be examined subsequently using the mooring data. The salinity maximum, which was 34.8 at station $\mathrm{AE}$, was reduced to 34.6 at $\mathrm{AC}$, indicating a weaker presence for the Kuroshio. Like station AE, the tidal currents at station $\mathrm{AC}$ were bottomtrapped for both the flood and ebb tides.

Station AW also featured a mode-2-like bulge in the 16$17^{\circ} \mathrm{C}$ water, which was somewhat sharper than the one observed at AC. The feature lasted from 12:30 to 16:00 on 14 August and displaced the isotherms about $100 \mathrm{~m}$ both upward and downward (Fig. 3a). Like the feature at AC, this feature was centered near $200 \mathrm{~m}$ depth and was accompanied by westward velocity in its core (Fig. 3c), consistent with a mode- 2 structure. There was a longer delay, about $5 \mathrm{~h}$, between the turn of the ebb tide and arrival of the lens. Assuming origins to the east, this is because the tidal fluctuations were nearly in phase at $\mathrm{AC}$ and $\mathrm{AW}$, but it took longer for internal motions to propagate to AW from the east. The extra $3 \mathrm{~h}$ delay was consistent with the propagation time needed for a mode-2-like structure to advance from $\mathrm{AC}$ to $\mathrm{AW}$. The tides at AW showed a complex structure with multiple cores distributed vertically throughout the water column (Fig. 3c, d). There were bottom jets like the other anchor stations, but there was more velocity in the upper water column as well.

\subsection{Moorings}

The fast-sampling moorings did a good job of resolving the high-frequency part of these mode- 2 structures. Three particularly good examples from 9, 12, and 14 August show that the mode-2 thermocline "bulges" observed at the anchor 

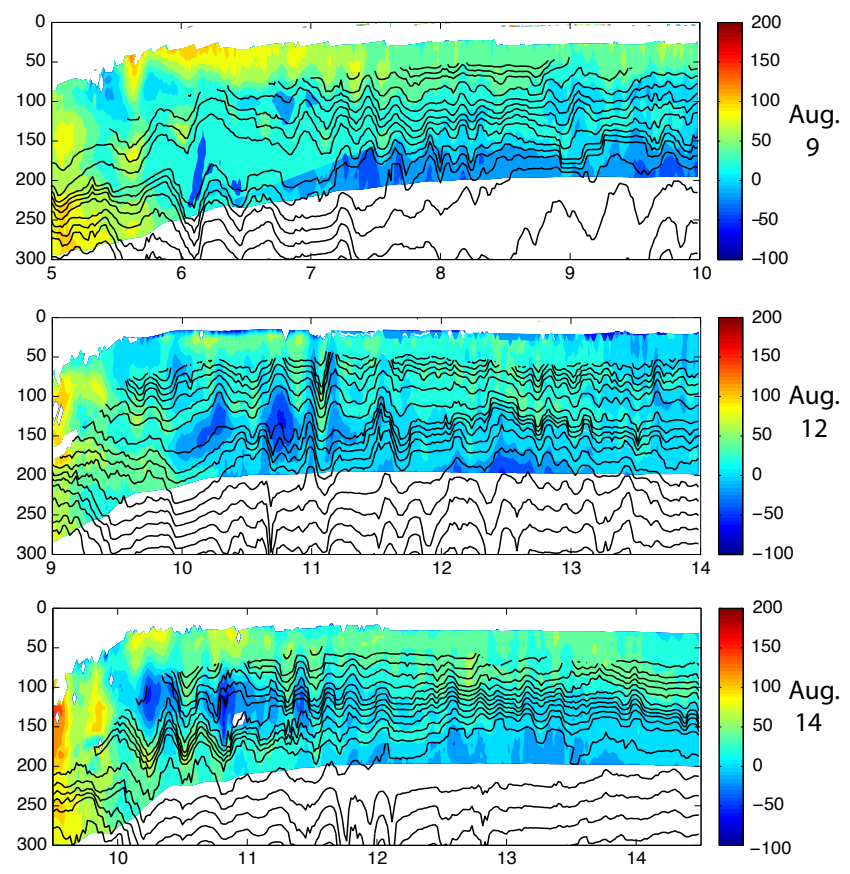

Figure 4. Isotherm displacements (black lines) over zonal velocity (color) for $5 \mathrm{~h}$ just past the peak ebb tide for 9 August (top), 12 August (middle), and 14 August (bottom).

stations were in fact NLIWs with a period of about $30 \mathrm{~min}$ (Fig. 4). The times of interest have been enlarged to show the correspondence between the isotherm displacements and velocity. On 9 August, a train of mode- 2 waves passed by between 06:00 and 08:30 (Fig. 4, top). The mode-2 packet was rank ordered in space and time, with about an hour between the first and second waves, decreasing to $20 \mathrm{~min}$ and then $15 \mathrm{~min}$ for the later waves. The wave amplitude likewise decreased down the wave train from $\pm 50 \mathrm{~m}$ in the lead wave to about $20 \mathrm{~m}$ in the last wave. The mode- 2 cores had westward (negative zonal) velocities of order $50 \mathrm{~cm} \mathrm{~s}^{-1}$ and opposing near-surface eastward velocities of order $80 \mathrm{~cm} \mathrm{~s}^{-1}$. Unfortunately, the region below the westward wave cores was not observed by the ADCP, although there are enough data to clearly delineate the westward maximum. On $12 \mathrm{Au}-$ gust, there was a train of at least four mode- 2 waves between 10:00 and 12:00 (Fig. 4, middle). Peak velocities were similar to 9 August in the westward core but weaker in the surface layer, about $50 \mathrm{~cm} \mathrm{~s}^{-1}$. The waves were less rank ordered, with all the waves arriving about 25 min apart. On $14 \mathrm{Au}-$ gust, the waves were again weakly rank ordered (as judged by isotherm displacements associated with westward (blue) velocity cores), with waves arriving at 10:15, 10:50, 11:10, and 11:20 (Fig. 4, bottom). The westward velocity in the core of these waves was once again about $50 \mathrm{~cm} \mathrm{~s}^{-1}$ and the eastward velocity above was about $80 \mathrm{~cm} \mathrm{~s}^{-1}$.
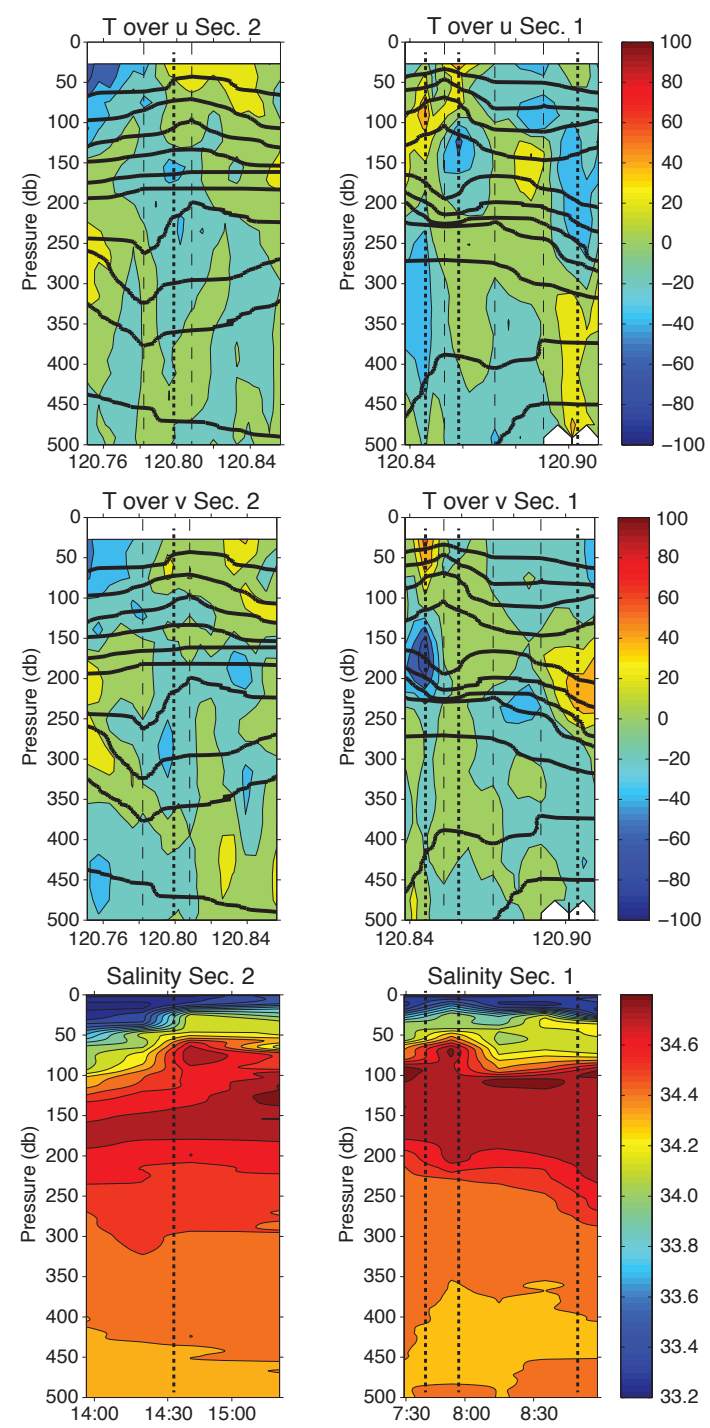

Figure 5. Temperature from the UCTD overlaid on the zonal (top) and meridional (middle) velocity from the ship's hull-mounted ADCP. The mean velocity profile has been removed from both components. The right panels are from Sect. 1 and the left panels from Sect. 2 as shown in Fig. 1b. The corresponding salinity sections are on the bottom. The top two panels are plotted against longitude and the bottom against the corresponding time. Dashed vertical lines indicate the station positions, including two on the borders. Dotted vertical lines indicate the wave core positions/times as indicated by velocity.

\subsection{Underway CTD}

Three samplings of mode- 2 structures were captured by the UCTD profiles and underway systems on 15 August. The first transect from 07:30 to 09:00 sampled three waves while the ship was steaming northeastward starting from $21.56^{\circ} \mathrm{N}$, $120.84^{\circ} \mathrm{E}$ (Fig. 1b). In chronological order, the first wave appeared at $07: 45$ near $120.85^{\circ} \mathrm{E}$ and was most obvious in the 


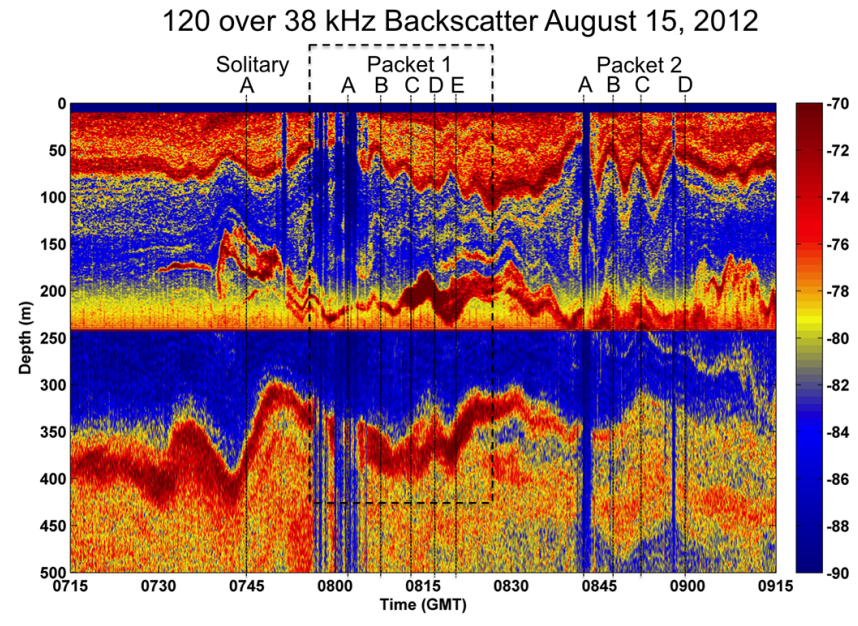

Figure 6. A composite of the $120 \mathrm{kHz}$ backscatter (top half) and $38 \mathrm{kHz}$ backscatter (bottom half) for the same time period as UCTD Sect. 1 (Fig. 5, right panels). The three waves visible in Fig. 5 correspond to the solitary wave at 07:45 and the lead waves in two packets that arrived at 08:00 and 08:45, respectively. The packet structure which was not revealed by the UCTD sampling is clearly evident here. Vertical blue lines are due to bubbles entrained beneath the ship by the wave itself, which temporarily blocked the instrument's transducer heads. The packet labeling across the top corresponds to the labeling used in the surface radar images (Fig. 7).

$v$ component (Fig. 5, middle right). The wave had a southward core centered near $160 \mathrm{~m}$ depth with an equally strong northward flow in the upper layer. This was the strongest of the three events and both southward and northward velocities exceeded $50 \mathrm{~cm} \mathrm{~s}^{-1}$. The second wave appeared at 08:00 near $120.86^{\circ} \mathrm{E}$ and was most clearly visible in the $u$ component (Fig. 5, top right). This wave was slightly weaker than the first, with westward core velocities of order $40 \mathrm{~cm} \mathrm{~s}^{-1}$ near $130 \mathrm{~m}$ and similar eastward velocities above. The wave was absent in the $v$ component, indicating that it was propagating mainly westward. The third wave intersected the ship's path around $08: 45$ near $120.90^{\circ} \mathrm{E}$. This wave was weaker than the second but had greater vertical extent, with a wide westward velocity core of order $30 \mathrm{~cm} \mathrm{~s}^{-1}$ spanning 125 to $250 \mathrm{~m}$ depth. The waves were also evident in the thermohaline structure: the first bulge in the isotherms centered near $120.85^{\circ} \mathrm{E}$ was actually due to the first two waves combined. The isotherm displacements (black lines) were symmetric, and were elevated by about $40 \mathrm{~m}$ in the upper portion of the wave and depressed by the same amount below. There was a corresponding bulge in the haline structure as well (Fig. 5, bottom right). Both isotherms and isohalines sloped downward between waves 2 and 3 . The third wave had broader but weaker isotherm displacements of about $\pm 20 \mathrm{~m}$ centered near $160 \mathrm{~m}$ depth.

In an effort to re-acquire the waves, the ship made a second transect steaming eastward along $21.56^{\circ} \mathrm{N}$ from $120.76^{\circ} \mathrm{E}$ to $120.85^{\circ} \mathrm{E}$ (Fig. 1b). Only one weak wave was observed at $14: 30$ near $120.80^{\circ} \mathrm{E}$ (Fig. 5, top left). This wave had a westward velocity of only $20 \mathrm{~cm} \mathrm{~s}^{-1}$ near $170 \mathrm{~m}$ and was associated with a weaker thermocline bulge of about $\pm 20 \mathrm{~m}$. During this transect the tide had turned to flood below $150 \mathrm{~m}$ depth but remained eastward above. These strongly sheared background currents distorted the wave such that the ship encountered the downward thermal displacements in the lower portion of the wave before the upward displacements in the upper half of the wave. By examining the ship's digitally recording radar (see details below), we determine this was most likely a second realization of the second wave in transect 1 , the first wave having already passed by to the south of transect 2 before the ship came along, while the third wave passed to the north. The ship likely sampled a more southerly portion of the wave crest, which may explain the weaker structure. The wave traveled $0.06^{\circ}$ in $6.5 \mathrm{~h}$, indicating a westward propagation speed of only $0.29 \mathrm{~m} \mathrm{~s}^{-1}$. This is much slower than the mode- 2 speed of $0.85 \mathrm{~m} \mathrm{~s}^{-1}$ computed from the CTD data, indicating the wave was still partially arrested by the ebb tide.

\subsection{Case studies}

Three mode- 2 wave events are now examined in additional detail by combining the above data sets with the underway observations of velocity, backscatter, and surface roughness. These data with high temporal resolution provide a more accurate description of the packet structure and propagation speed and direction of the waves. A total of five such events were examined using similar techniques but in the interest of brevity only three are discussed here. The backscatter plot for the three events, which are the same ones observed in the UCTD data described above, shows that the three wave events consisted of a solitary wave arriving at 07:45 followed shortly thereafter by two wave packets arriving at 08:00 and 08:45 (Fig. 6). These were all mode- 2 waves of the convex type, i.e., consisting of a bulge in the thermocline. The vertical dotted lines show the position of the surface breaking waves as indicated by the ship's radar and photography (Fig. 7). The breaking waves were located in the convergent zone trailing the wave peaks, in a manner similar to mode-1 elevation waves (Liu et al., 1998; Yang et al., 2009, 2010; Ramp et al., 2012). The vertical blue lines are regions where the transducer heads were masked by bubbles advected under the ship by the downwelling velocity in the waves, resulting in no signal. This phenomenon was most prevalent when the wave peaks were close to the sea surface.

The solitary wave appeared to have a roll-up centered between 150 and $200 \mathrm{~m}$ depth, suggesting wave breaking and overturning in the wave core (Fig. 6). The two following packets reveal a better-resolved view of the waves captured by the UCTD (Fig. 5). The first packet contained at least five waves and the second four. The waves were evenly spaced in time about $5 \mathrm{~min}$ apart and were not rank-ordered. Subsequent waves in each packet became successively deeper 

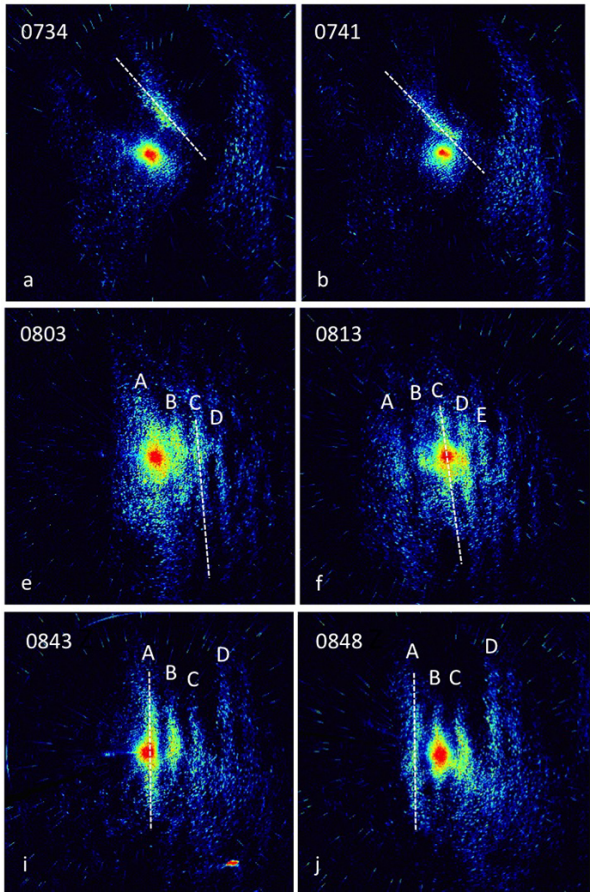
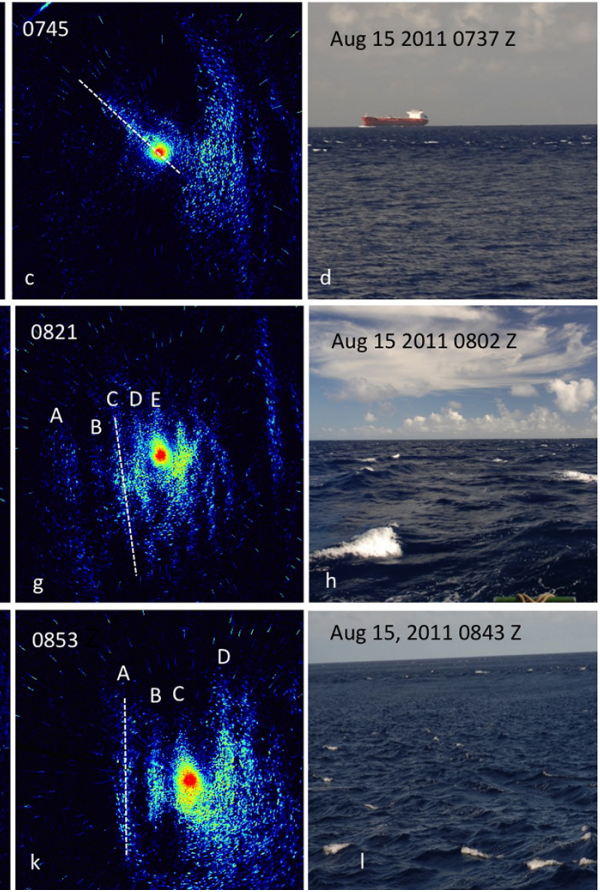

Figure 7. Time series of ship's radar images and sea surface photographs corresponding to the three events highlighted in Fig. 6. The top panels show the solitary wave, the middle panels Packet 1 , and the bottom panels Packet 2.

Table 1. Summary of mode-2 wave properties.

\begin{tabular}{|c|c|c|c|c|c|c|c|c|c|c|c|c|}
\hline Date & Time & $\begin{array}{l}\text { Time relative } \\
\text { to } \mathrm{M}\end{array}$ & Location & $\begin{array}{l}\text { No. of waves } \\
\text { per packet }\end{array}$ & $\begin{array}{l}\text { Depth range } \\
\text { (m) }\end{array}$ & $\begin{array}{l}\text { Core depth } \\
\text { (m) }\end{array}$ & $\begin{array}{l}\text { Isothermal } \\
\text { displacements } \\
\text { (m up, down) }\end{array}$ & $\begin{array}{l}\text { Core speed } \\
\left(\mathrm{m} \mathrm{s}^{-1}\right)\end{array}$ & $\begin{array}{l}\text { Upper layer } \\
\text { speed } \\
\left(\mathrm{m} \mathrm{s}^{-1}\right)\end{array}$ & $\begin{array}{l}\text { Lower layer } \\
\text { speed } \\
\left(\mathrm{m} \mathrm{s}^{-1}\right)\end{array}$ & $\begin{array}{l}\text { Prop. } \\
\text { speed } \\
\left(\mathrm{m} \mathrm{s}^{-1}\right)\end{array}$ & $\begin{array}{l}\text { Prop. dir. } \\
\text { deg true }\end{array}$ \\
\hline 9 Aug & 06:05 & $06: 05$ & $\mathrm{M}$ & 5 & $50-300$ & 170 & 50,50 & $0.5^{\circ} \mathrm{W}$ & $100^{\circ} \mathrm{E}$ & - & - & - \\
\hline $12 \mathrm{Aug}$ & $06: 37$ & $07: 49$ & $A C$ & 3 & $5-225$ & 130 & 65,75 & & & & 0.67 & 279 \\
\hline 12 Aug & $10: 20$ & $10: 20$ & $\mathbf{M}$ & 4 & $50-210$ & 130 & 40,30 & $0.5^{\circ} \mathrm{W}$ & $0.8^{\circ} \mathbf{E}$ & - & - & - \\
\hline $14 \mathrm{Aug}$ & $10: 10$ & $07: 48$ & $A W$ & 4 & $30-250$ & 170 & 60,60 & $0.5^{\circ} \mathrm{W}$ & $0.5^{\circ} E$ & - & 0.69 & 257 \\
\hline 14 Aug & $10: 10$ & $10: 10$ & M & 4-7 & $50-300$ & 125 & 60,60 & $0.5^{\circ} \mathrm{W}$ & $0.8^{\circ} \mathbf{E}$ & - & - & - \\
\hline 15 Aug & $07: 40$ & $06: 28$ & UCTD & 1 & $50-400$ & 170 & 30,50 & $0.5^{\circ} \mathrm{S}$ & $0.6^{\circ} \mathrm{N}$ & $0.1^{\circ} \mathrm{N}$ & 0.32 & 222 \\
\hline $15 \mathrm{Aug}$ & 08:00 & $07: 33$ & $U C T D$ & 4 to 5 & $40-380$ & 130 & 40,40 & $0.5^{\circ} \mathrm{W}$ & $0.4^{\circ} \mathrm{E}$ & $0.1^{\circ} \mathrm{E}$ & 0.29 & 266 \\
\hline 15 Aug & 08:40 & 09:54 & UCTD & 5 to 8 & $30-340$ & 170 & 30,30 & $0.4^{\circ} \mathrm{W}$ & $0.1^{\circ} \mathrm{E}$ & $0.2^{\circ} \mathrm{E}$ & est. 0.29 & 268 \\
\hline
\end{tabular}

in Packet 1 but remained about the same depth in Packet 2 . Time series of the surface signatures due to the nonlinear internal waves reveal additional information regarding their scales and propagation speeds and directions (Fig. 7). The solitary wave was propagating SW towards $222^{\circ}$ true north (Fig. 7a-c). This trajectory was much more southward than the other packets observed. The wave moved $170 \mathrm{~m}$ in $660 \mathrm{~s}$ (11 $\mathrm{min})$ past a stationary ship, which indicates a speed of $0.26 \mathrm{~m} \mathrm{~s}^{-1}$. This is quite slow for a large-amplitude mode2 wave and is attributed to the opposing eastward tide. The radar backscatter was produced by the breaking waves on the sea surface as shown in the photograph (Fig. 7d). The wave can be located unambiguously due to the fortuitous presence of the large container ship that was also visible in the radar just off the top of Fig. 7a.

The OR3 intersected packet 1 just 18 min later (Fig. 7eh). There were at least five waves in this packet, but with others continuously coming into view as the packet passed the research vessel. The waves were only a few hundred meters apart and passed the OR 3 roughly every $5 \mathrm{~min}$. The waves were evenly spaced and did not appear to be rank ordered in time. The entire packet was moving towards $266^{\circ}$ at roughly $0.3 \mathrm{~m} \mathrm{~s}^{-1}$. This is in very close agreement with the speed ascertained from the two UCTD transects $\left(0.29 \mathrm{~m} \mathrm{~s}^{-1}\right)$ and slower than the computed mode- 2 speed. This can be attributed once again to the opposing ebb tide that slowed down the waves. The wave spacing for packet 2 (Fig. 7i-k) was similar to packet 1 , but with a slightly different direction $\left(268^{\circ}\right)$. Packet 2 appeared to be stationary (arrested) on the sea surface for some time but then started moving also at about $0.29 \mathrm{~m} \mathrm{~s}^{-1}$. All four internal waves in this packet produced breaking waves on the sea surface, leading to the remarkable photograph (Fig. 71) that shows all four rows of breaking waves A-D at once, separated by slicks in between. 


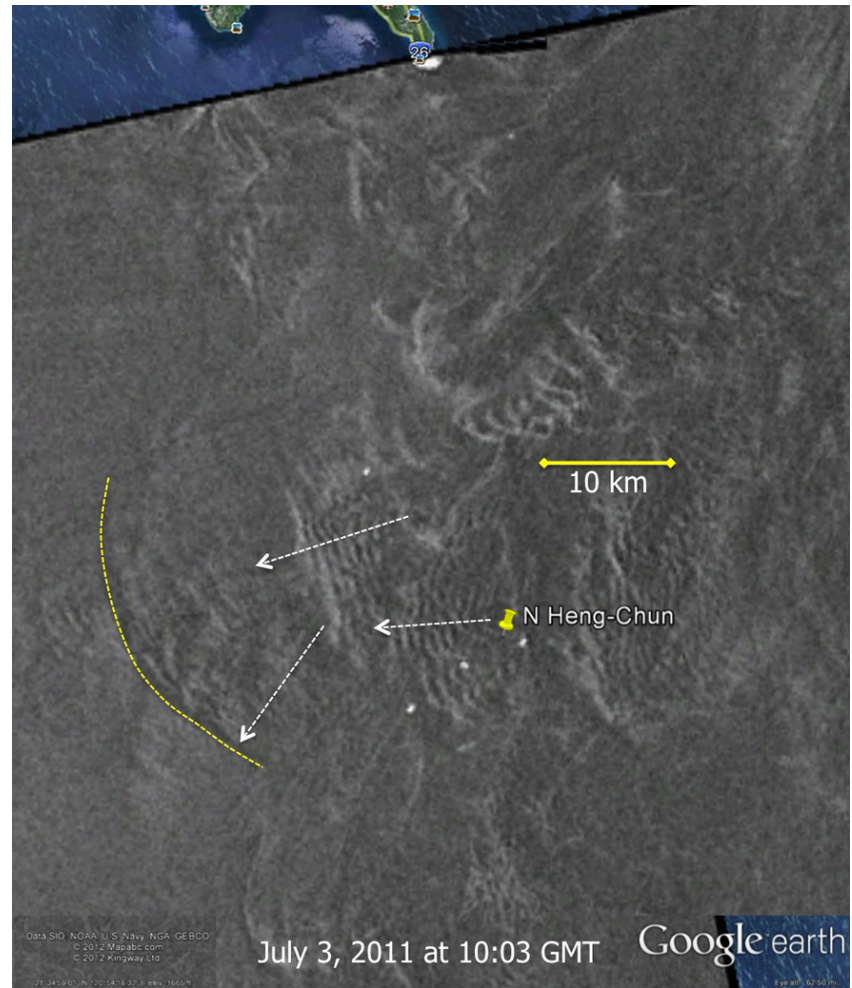

Figure 8. Satellite synthetic aperture radar (SAR) image from 3 July 2011 showing a solitary wave leading two packets, similar to the situation observed in situ on 15 August. The image was obtained during a similar phase of the tide: 3 days after new moon for 3 July and 3 days past full moon on 15 August. The push-pin indicates the mooring position.

Satellite synthetic aperture radar (SAR) imagery is unfortunately not available for the mid-August 2011 time period. One outstanding image is available however from 3 July 2011 (Fig. 8). This image was obtained at a time that was dynamically similar to 15 August: 3 July was 3 days after new moon, and 15 August was 3 days after full moon. The ocean stratification is not too different between July and August. Even the timing is fortuitous since the image was acquired at 10:03 Z, the same time frame when the 15 August waves were observed. The image depicts a scenario that closely resembles the observed waves on 15 August 2011. There was a leading solitary wave (yellow dotted line) that would appear to be much more southward at the mooring location (yellow push-pin). Behind the solitary wave, two packets are shown with many evenly spaced waves per packet and slightly different propagation directions. A third packet trails farther behind to the east, which we cannot comment on from the 15 August data. The solitary wave and the first two packets however are an excellent match for what was observed on 15 August. The in situ data and SAR imagery both suggest multiple generation sites around the complex topography to the east of the mooring location. These packets trending WSW and another trending WNW on 12 August (see Table 1) are consistent with origins in the two channels separated by the high point just east of the mooring (Fig. 1b). The along-crest scales in the image (and observed onboard by eye) were order 5-10 km, about the same width as the local channels. This suggests that the waves were constrained by the taller topography to the north and south.

The wave characteristics as best we can estimate them from the available data are summarized in Table 1. The arrival time is provided for each wave event at the location where it was observed (mooring, anchor stations, or UCTD). The time when the wave would have passed the mooring given the observed phase speeds is also given to normalize the arrival times. Three classes of waves emerge: The first category passed by the mooring in the vicinity of 06:0506:28 (normal font in Table 1). This wave was sometimes solitary (15 August) and sometimes not (9 August). The second category passed the mooring at 07:33-07:49 (italic font). These waves had the fastest apparent propagation speed and moved slightly south of west. These waves are likely analogous to the first packet in the satellite image (Fig. 8). The third category passed by the mooring at 09:54-10:20 (bold font). These waves moved towards a slightly more westward direction and likely correspond to the second packet in the image.

\section{Discussion}

\subsection{Energy balance}

The fundamental energy balance of interest over the ridge is that the barotropic-to-baroclinic energy conversion must equal the flux divergence plus the local turbulent dissipation. This may be expressed mathematically as

$$
\left.\nabla H \cdot \boldsymbol{u}_{\mathrm{BT}}^{\prime} p^{\prime}\right|_{z=-H}=\nabla \cdot \boldsymbol{F}_{E}+\varepsilon,
$$

where $\nabla H \cdot \boldsymbol{u}_{\mathrm{BT}}^{\prime}$, the bottom slope times the horizontal barotropic velocity, is a proxy for the local vertical velocity, $\left.p^{\prime}\right|_{z=-H}$ is the pressure perturbation at the bottom, $\varepsilon$ is the dissipation, and

$$
\boldsymbol{F}_{E}=\boldsymbol{u}^{\prime}\left(p^{\prime}+\mathrm{HKE}+\mathrm{APE}\right)
$$

is the energy flux expressed as the sum of the pressure work term $\boldsymbol{u} p^{\prime}$ and the advection of horizontal kinetic (HKE) and available potential energy (APE) density (Nash et al., 2006). Here $u^{\prime}$ and $p^{\prime}$ are the baroclinic velocity and pressure fluctuations computed as:

$$
\boldsymbol{u}^{\prime}(z, t)=\boldsymbol{u}(z, t)-\bar{u}(z)-\frac{1}{H} \int_{-H}^{0}[\boldsymbol{u}(z, t)-\bar{u}(z)] d z
$$



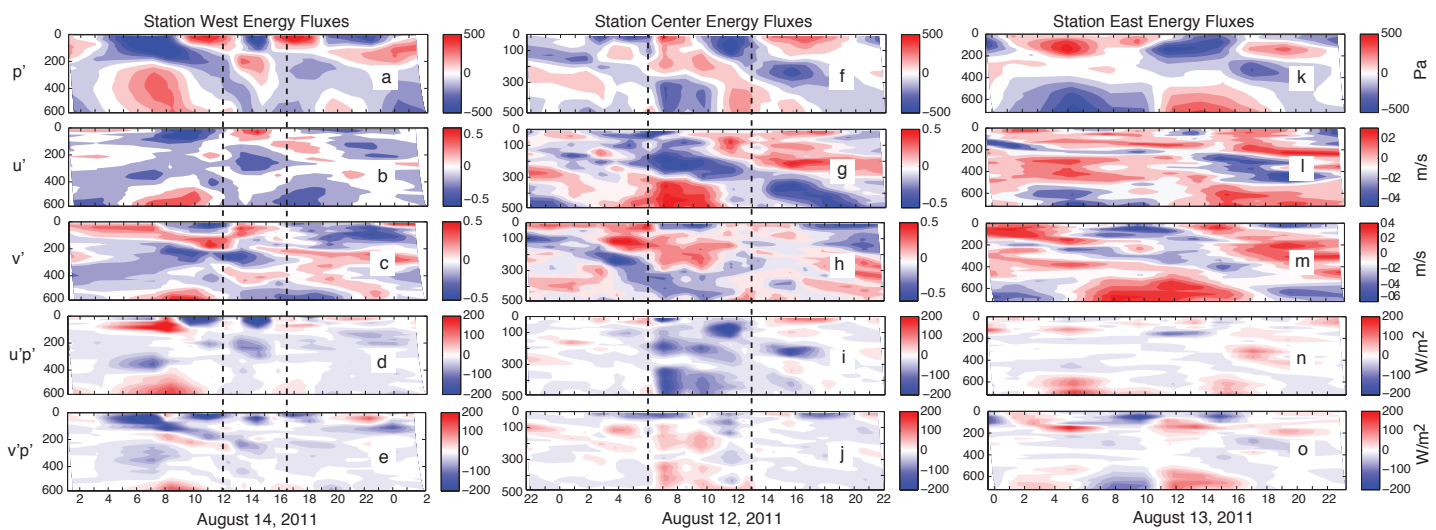

Figure 9. Terms in the energy flux equation for anchor stations west (left column), center (middle), and east (right). From top to bottom, the panels are the baroclinic pressure fluctuation, zonal velocity fluctuation, meridional velocity fluctuation, and the corresponding pressure work terms. The vertical dotted lines indicate times when the mode- 2 waves were present.
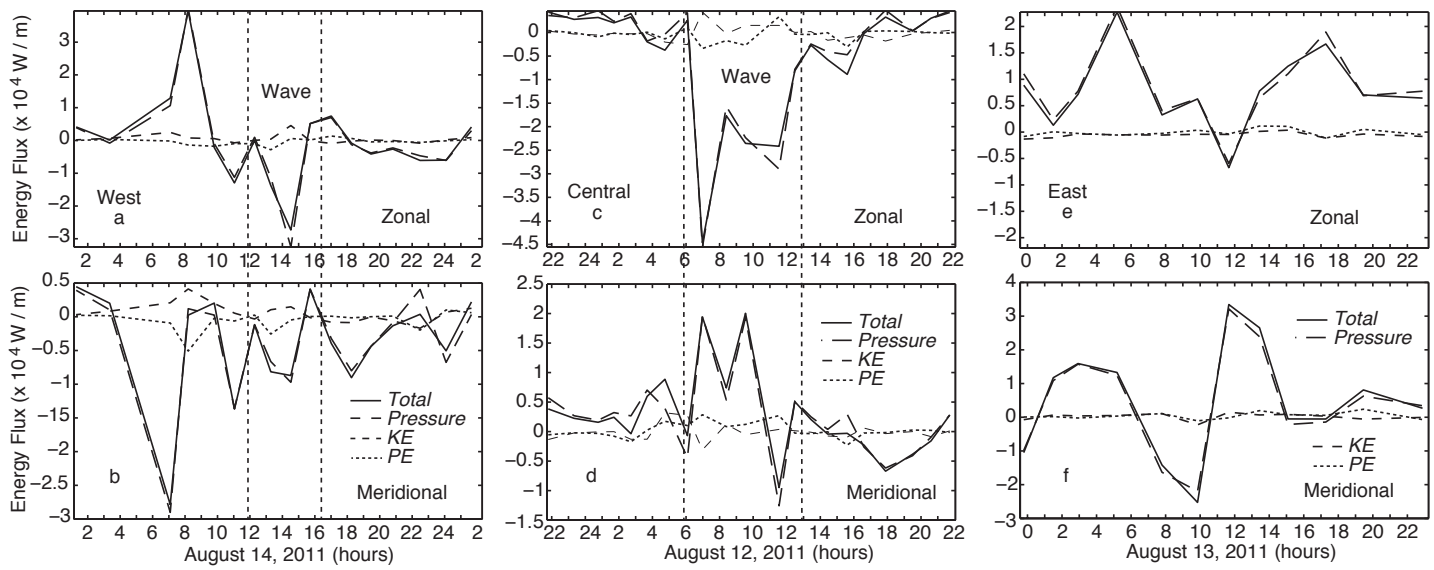

Figure 10. Vertically integrated terms in the energy flux equation, for stations Anchor West (left), Center (middle) and East (right). For example, the heavy dashed line (pressure work) in (a) is the vertical integral of Fig. 9d.

and

$p^{\prime}(z, t)=g \int_{z}^{0} \rho^{\prime}(\zeta, t) d \zeta-\frac{g}{H} \int_{-H}^{0} \int_{z}^{0} \rho^{\prime}(\zeta, t) d \zeta d z$,

where

$\rho^{\prime}(z, t)=\rho(z, t)-\bar{\rho}(z)$

is the density anomaly with respect to the time-mean density profile. In all the equations, an over bar indicates the temporal mean and the last term satisfies the baroclinicity requirement that the primed quantities integrate to zero over the entire water column (Kunze et al., 2002; Lee et al., 2006).

The HKE and APE can then be computed as

$\mathrm{HKE}=\rho_{0}\left(u^{\prime 2}+v^{\prime 2}\right) / 2$,

$$
\mathrm{APE}=\frac{1}{2} \frac{g^{2} \rho^{\prime 2}}{\rho_{0} N^{2}}
$$

where $\rho_{0}$ is the mean density, $g$ is the acceleration of gravity and $N^{2}$ is the buoyancy frequency. For the small amplitude, linear, hydrostatic case the flux equation is often approximated as

$\boldsymbol{F}_{E}=\boldsymbol{u}^{\prime} p^{\prime}$,

but since it is not obvious that this approximation is valid on the Heng-Chun Ridge, all three terms of the flux equation were computed. Most of the terms in these equations can be computed from the data via established techniques (Nash et al., 2005, 2006; Lee et al., 2006). The exception is the flux divergence term: since there was only one mooring and the anchor stations did not overlap in time, the observations necessary to compute the flux divergence were not obtained. A rough approximation was made by assuming the 


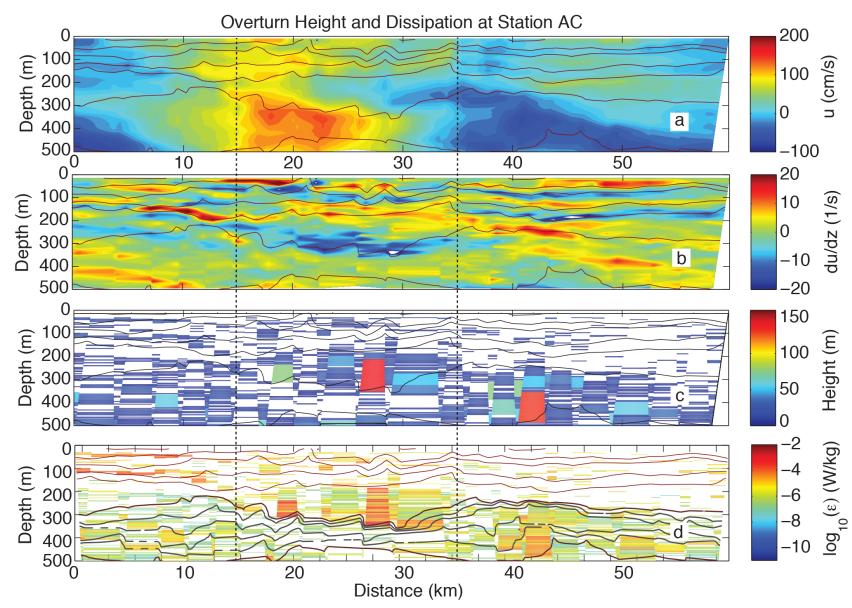

Figure 11. The zonal velocity (a) and vertical shear (b) represented in color plotted with density (solid black lines) as a function of pseudo-distance for anchor station AC. The $x$ axis was converted from time to distance using the observed propagation speed $\left(0.67 \mathrm{~m} \mathrm{~s}^{-1}\right)$ of the mode- 2 wave (Table 1$)$. The bottom two panels are the overturn heights (c) and turbulent dissipation (d) determined via Thorpe scaling. The density contour intervals on the bottom plot represent 1.0 sigma- $\mathrm{T}$ units (red) and 0.5 sigma-T units (gray). The dotted vertical lines indicate the horizontal bounds of the mode- 2 wave used in the energy and flux calculations.

tides were regular and that the daily averaged, vertically integrated fluxes for 14 August were similar to 12 August. The flux divergence can then be estimated by differencing the fluxes computed at stations AC and AW. The number at least provides a point of comparison for the flux divergence computed using the numerical model, described subsequently.

The anchor stations worked best for the energy calculations due to their uniform vertical sampling of $u, v, T$, and $S$, which allows easy calculation of density and the mean and primed quantities. The density anomaly $\rho^{\prime}(z, t)$ was first computed by removing the time mean vertical profile averaged over the duration of each anchor station, about $24 \mathrm{~h}$. The velocity and pressure fluctuations were then calculated using Eqs. (3) and (4) and the terms in the energy flux equation using Eqs. (2), (6), and (7).

The perturbation pressure, horizontal velocities and pressure work terms for the three anchor stations show the different conditions that prevailed at the three locations (Fig. 9). The vertically integrated advection of HKE and APE was indeed near zero at all three stations (Fig. 10) and those terms have therefore been omitted from Fig. 9. This was consistent with results from a related study near abrupt topography in the Monterey Bay, CA where the hydrostatic pressure work was found to be the dominant term by far (Kang and Fringer, 2012). This disagrees with the Oregon shelf where all the terms in Eq. (2) were found to be important for highly nonlinear waves (Moum et al., 2007). This is perhaps a product of the wave packets being under-sampled by the anchor stations, thus appearing to be less nonlinear than they actually were. At station AW (Fig. 9a-e) the flux was dominated by two time periods, namely during the eastward tide centered at 08:00 and the westward mode- 2 wave centered near 14:30. During the eastward tide, the zonal velocity and pressure fluctuations were positively correlated resulting in a positive (eastward) energy flux (Figs. 9d, 10a). When the mode2 wave was present, positive pressure fluctuations (due to anomalously warm water near $200 \mathrm{~m}$ ) were associated with negative velocity fluctuations resulting in a westward energy flux. The mode- 2 wave flux was nearly equal and opposite to the tidal flux at about $-3 \times 10^{4} \mathrm{~W} \mathrm{~m}^{-1}$. The meridional flux also made a contribution (Figs. 9e, 10b) such that the total flux was southeastward in the tide and southwestward in the wave. This was in keeping with the observed propagation direction of the wave (Table 1, line 4). The observed fluxes were very large but in keeping with other observations further south along the Heng-Chun Ridge (Alford et al., 2011). The flux due to the flood tide (after 16:00) was small and southwestward.

In contrast, the tidal flux at Station $\mathrm{AC}$ was negligible (Figs. 9f-j, 10c, d). This was due to a banded beam-like structure of the tide at this location (Fig. 9f-h) such that the positive and negative contributions to the energy flux canceled out when integrated over the water column. Most of the energy flux at AC was carried northwestward by the mode- 2 wave (Figs. 9i, j, 10c, d). The direction, just slightly north of west, was again consistent with observed propagation direction of the wave (Table 1, line 2). The magnitude at $-4.5 \times 10^{4} \mathrm{~W} \mathrm{~m}^{-1}$ was slightly larger than at AW. This is difficult to interpret since the same wave was not observed at both locations. It may indicate some flux divergence between stations AC and AW, but may also simply be due to $14 \mathrm{Au}-$ gust (AW) being 2 days past the spring tide which occurred on the 12th (AC) (Fig. 1c). The slightly weaker forcing would presumably lead to weaker internal tides and NLIWs on the 14th with respect to the 12th.

Station AE was located east of the cross-ridge channel on the $1000 \mathrm{~m}$ isobath, and was thus less constrained meridionally than the other two stations. Unlike stations AC and AW, the flux at $\mathrm{AE}$ was dominated entirely by the tide, with no contribution from mode- 2 waves. The pressure and velocity fluctuations were positively correlated on the westward tide and negatively on the eastward tide, resulting in eastward energy flux on the westward tide and vice versa (Figs. 9k, 1, n, 10e). The meridional component was slightly out of phase with the zonal component. The brief and narrow southward component of the bottom-trapped tide was positively correlated with pressure and resulted in a northward energy flux. The broader, stronger northward component of the tide spanning 06:00-17:00 overlapped with times of both negative and positive pressure resulting in both southward and northward flux (Figs. 9k, m, o, 10f). The average flux over the entire length of the record was northeastward. Some of this flux may be due to the mean flow in the Kuroshio Current which 
was not completely removed using the techniques employed on a short (nominally 1-day) record.

\subsection{Turbulent dissipation}

Purpose-built instrumentation for measuring the turbulent dissipation was not available during the cruise, however the dissipation can be inferred from the CTD/LADCP profiles using the Thorpe scaling method (Thorpe, 1977; Dillon, 1982; Klymak et al., 2011; Alford et al., 2011). Side-byside comparisons indicate this method works well when compared to the Gregg-Henyey method (Nash et al., 2007). The Thorpe-sorted displacements are found by rearranging the observed profile of potential density, conserving mass and heat, to form a stable profile (Thorpe, 1977). From the practical standpoint, the method consists of ordering an observed potential density profile, which may contain inversions, into a stable monotonic profile which contains no inversions (Dillon, 1982). The Thorpe "displacement" is the vertical distance one must move each water parcel to achieve this stable profile. The Thorpe "scale" $\mathrm{L}_{\mathrm{T}}$ is the root mean square value of all the displacements within an overturn. The RMS value is used rather than the maximum displacement since it is a more statistically stable estimator of three-dimensional turbulence (Dillon, 1982). The turbulent dissipation rate $\varepsilon$ and the diapycnal diffusivity $\mathrm{K}_{\rho}$ can then be found from the Thorpe scales using (Osborn, 1980; Alford et al., 2011; many others)

$\varepsilon=\left(L_{\mathrm{T}}\right)^{2} N_{\mathrm{S}}^{3}$

and

$K_{\rho}=\Gamma \varepsilon N_{\mathrm{S}}^{-2}$,

where $N_{\mathrm{S}}$ is the Thorpe-sorted (stable) buoyancy profile and $\Gamma$ is the mixing efficiency, generally taken to be 0.2 .

The results for station AC show the typical locations of the high-dissipation regions with respect to the density and velocity structure across the top of the ridge (Fig. 11). Large overturns were observed in two regions: (a) in the core of the mode- 2 waves where large roll-ups were also observed in the backscatter data (cf. Fig. 6, solitary wave A); and (b) within the core of the westward and upslope surging tidal bore itself. The largest overturns were $140 \mathrm{~m}$ tall in the core of the mode- 2 wave centered near kilometer 27 and $300 \mathrm{~m}$ depth (Fig. 11c). The second largest overturn, $120 \mathrm{~m}$ tall, occurred at the bottom near kilometer 41 in the core of the westward tidal bore (Fig. 11a, c). These overturns were order $25 \%$ of the water depth. The density structure indicates horizontal scales of about $2.5 \mathrm{~km}$ for the overturns. The numerical model (discussed subsequently) also shows breaking internal motions inside the tidal bore. The near-bottom high-turbulence region in Fig. 11d may in fact be a remnant of a breaking lee wave coming back over the top of the ridge from the east upon the turning of the tide. Additionally, high dissipation was also found associated with the high shear (Fig. 11b) and strong stratification in the nearsurface layers between kilometers 0 and 15 (Fig. 11d). The overturns there were moderate in size $(20 \mathrm{~m})$ but produced large dissipation due to the high values of $N_{\mathrm{S}}^{3}$. The large overturns were associated with turbulent dissipation of order $10^{-4}-10^{-3} \mathrm{~W} \mathrm{~kg}^{-1}$, which was very high but within the bounds of other regional observations. Farther south along the Heng-Chun Ridge near $20^{\circ} 30 / \mathrm{N}$ in water $1800 \mathrm{~m}$ deep, the maximum dissipation was order $10^{-5} \mathrm{~W} \mathrm{~kg}^{-1}$ (Alford et al., 2011). These were near-bottom values observed close to the spring tide. In breaking lee waves to the east of the LanYu Ridge between the Batan and Itabayat Islands, the dissipation reached $10^{-2} \mathrm{~W} \mathrm{~kg}^{-1}$ (Pinkel et al., 2012). The very high values of $\varepsilon$ observed at station AC suggest that breaking internal waves were the turbulence generating mechanism.

The high-dissipation regions at the other anchor stations (not shown) were similar to station AC. At AW, the largest overturn in the mode- 2 wave was about $80 \mathrm{~m}$, and the largest overturns ranging from 100 to $130 \mathrm{~m}$ tall were in the upslope (eastward at AW) tidal bore. The peak values of the dissipation were similar but slightly smaller than at station AC. The highest dissipation at AE $\left(10^{-4} \mathrm{~W} \mathrm{~kg}^{-1}\right)$ was within and beneath the Kuroshio above $150 \mathrm{~m}$ depth, as has been previously reported by other investigators (Rainville and Pinkel, 2004). Overturns exceeding $100 \mathrm{~m}$ in height were observed in the upslope (westward) tidal bore, but these overturns produced less dissipation than at $\mathrm{AC}$ and $\mathrm{AW}$ due to weaker stratification at $1000 \mathrm{~m}$ depth.

With some reservations, the pieces are now in place to compute the energy budget (Eq. 1) based on the conversion, flux divergence, and dissipation. The challenge for the conversion was how to choose the most appropriate bottom slope given the oscillating tide and extremely rough topography (Fig. 1). Given that the conversion is a large-scale process over the ridge, the large-scale bottom slope of .018 was used and steeper, smaller-scale portions of the bottom slope were ignored. The barotropic velocity was computed as the vertical average of the LADCP data at each anchor station. Using these numbers, the barotropic-to-baroclinic tidal conversion was found to be $2.26 \mathrm{~W} \mathrm{~m}^{-2}$ at Station AW and $3.41 \mathrm{~W} \mathrm{~m}^{-2}$ at Station AC. The difference in the barotropic tide between $\mathrm{AC}$ and $\mathrm{AW}$ could be spatial but could also be temporal due to the decreasing fortnightly envelope at the time the observations were obtained. The average value between the two stations was $2.8 \mathrm{~W} \mathrm{~m}^{-2}$. The dissipation in the mode- 2 wave at Station AC was found by vertically integrating over the center of the wave at kilometer 28 in Fig. 11d (and similarly for station $\mathrm{AW}$ ) and was found to be $1.5 \mathrm{~W} \mathrm{~m}^{-2}$. From Fig. 10a and $\mathrm{c}$, the flux divergence was computed as $1.5 \times 10^{4} \mathrm{~W} \mathrm{~m}^{-1}$ over $7500 \mathrm{~m}$ or $2 \mathrm{~W} \mathrm{~m}^{-2}$. While this is an admittedly crude estimate of the flux, it may be useful as a comparison point for the model flux divergence to be computed subsequently. 
Table 2. Total energy in the mode- 2 waves.

\begin{tabular}{lllllll}
\hline & $\begin{array}{l}\text { Integration depth } \\
(\mathrm{m})\end{array}$ & $\begin{array}{l}\text { Integration distance } \\
(\mathrm{km})\end{array}$ & $\begin{array}{l}\mathrm{KE} \\
\mathrm{MJ} \mathrm{m}^{-1}\end{array}$ & $\begin{array}{l}\mathrm{PE} \\
\mathrm{MJ} \mathrm{m}^{-1}\end{array}$ & $\begin{array}{l}\text { Total } \\
\mathrm{MJ} \mathrm{m}^{-1}\end{array}$ & $\mathrm{KE} / \mathrm{PE}$ \\
\hline $\mathrm{AC}$ & $10-490$ & $15-35$ & 660 & 300 & 960 & 2.2 \\
$\mathrm{AW}$ & $10-580$ & $25-35$ & 230 & 190 & 420 & 1.2 \\
\hline
\end{tabular}

The terms in the energy budget thus become

$$
\begin{aligned}
& \left.\nabla H \cdot \boldsymbol{u}_{\mathrm{BT}} p^{\prime}\right|_{z=-H}=\nabla \cdot \boldsymbol{F}_{E}+\varepsilon \\
& 2.8 \approx 2.0+1.5=3.5 \mathrm{~W} \mathrm{~m}^{-2} .
\end{aligned}
$$

Given the error involved, these numbers are approximately balanced and within the range of $1-3 \mathrm{~W} \mathrm{~m}^{-2}$ computed for all three terms by Alford et al. (2011) further south on the Heng-Chun Ridge. The flux divergence implied by a balanced energy equation would be only $1.3 \mathrm{~W} \mathrm{~m}^{-2}$. The independently computed estimate $\left(2.0 \mathrm{~W} \mathrm{~m}^{-2}\right)$ is likely high due to the decreased barotropic tidal forcing on 14 August with respect to 12 August (Fig. 1d), which would result in weaker internal tides and mode- 2 high-frequency waves. This means that the wave observed at station AW on the 14th was likely smaller at station $\mathrm{AC}$ than the wave observed there on the 12th, leading to a smaller flux divergence than if truly synoptic observations had been available. Additional error may also be accounted for by the nonlinear and non-hydrostatic terms in the energy equation, which have not been included. The ratio $q$ of dissipation to total conversion was about 0.53 at this location vs. $0.39-0.50$ farther south along the ridges (Jan et al., 2008; Alford et al., 2011). These values represent very high dissipation with respect to other global locations.

The total energy in the mode- 2 waves at stations AW and $\mathrm{AC}$ was computed by converting Fig. 10a-j from time to space using the observed wave propagation speeds $(0.69$ and $0.67 \mathrm{~m} \mathrm{~s}^{-1}$, respectively) and then integrating over depth and wavelength. Wavelength is taken to be the width of the mode-2 thermocline bulge at each anchor station (vertical dotted lines in Fig. 10). Thus, the horizontal integration is understood to represent the total energy in a packet of high-frequency nonlinear waves. The result (Table 2) shows about $960 \mathrm{MJ} \mathrm{m}^{-1}$ of pseudo-energy $(\mathrm{KE}+\mathrm{PE})$ at $\mathrm{AC}$ vs. $420 \mathrm{MJ} \mathrm{m}^{-1}$ at $\mathrm{AW}$. The energy at $\mathrm{AW}$ was approximately equipartitioned, with KE slightly exceeding PE with a ratio of 1.2. This is similar to other field studies of nonlinear internal waves (Scotti et al., 2007; Moum et al., 2007). Using numerical simulations, Lamb and Nguyen (2009) found $\mathrm{KE} / \mathrm{PE}$ ratios as high as 1.3 when the thermocline depth was a small fraction of the water depth. At station AC however the KE/PE ratio was 2.2, which was anomalous and not in agreement with linear or weakly nonlinear theory. This may be due to higher-order nonlinear and non-hydrostatic terms that cannot be estimated from this data set. It may also be due to the mode- 2 structure of the wave, which differs from previous studies where the waves were all one-sided (either mode-1 depression or elevation waves). Relative to other observations, the energy magnitude was much smaller than the $1800 \mathrm{MJ} \mathrm{m}^{-1}$ observed in a mode-1 SCS transbasin wave (Klymak et al., 2006) but larger than the $87 \mathrm{MJ} \mathrm{m}^{-1}$ in the waves northeast of Taiwan (Duda et al., 2013) and much larger than the waves on the New England continental shelf $\left(7 \mathrm{MJ} \mathrm{m}^{-1}\right.$ ) (Shroyer et al., 2010) or bottom-trapped waves on the Oregon shelf $\left(20 \mathrm{MJ} \mathrm{m}^{-1}\right)$ (Moum et al., 2007).

Both $\mathrm{KE}$ and $\mathrm{PE}$ were greater at $\mathrm{AC}$ than $\mathrm{AW}$, such that the total energy at $\mathrm{AC}$ exceeded that at $\mathrm{AW}$ by $540 \mathrm{MJ} \mathrm{m}^{-1}$. Much of this change can be accounted for by the very high dissipation in the westward-propagating waves. If the observed dissipation of $1.5 \mathrm{~W} \mathrm{~m}^{-2}$ were allowed to act over the entire packet length $\left(2.0 \times 10^{4} \mathrm{~m}\right)$ and the time required for the wave to propagate from $\mathrm{AC}$ to $\mathrm{AW}(3.63 \mathrm{~h})$ then $392 \mathrm{MJ} \mathrm{m}^{-1}(72 \%)$ of the energy loss between moorings could be accounted for. This furthermore implies that only $8.9 \mathrm{~h}$ would be required for all the energy observed at AC $\left(960 \mathrm{MJ} \mathrm{m}^{-1}\right)$ to be dissipated. This is consistent with the idea that higher-mode waves dissipate very quickly (Shroyer et al., 2010) and suggests that these waves, despite their very high initial energy content, remain a fairly local phenomenon over the northern Heng-Chun Ridge. This appears to be supported by the available satellite imagery, in which waves like the ones visible in Fig. 8 have not been observed farther to the west. The site appears to be more important for tidal dissipation than for transbasin wave generation.

\subsection{Model-data comparisons}

In a previous work based on a single realization, RYRB12 found that the flow over the Heng-Chun Ridge in this location (based on the Froude number) was supercritical to mode2 but not mode- 1 waves. Thus, mode- 2 and higher could be arrested by the strong eastward tide occurring once per day, releasing a turbulent bore and higher-mode waves when the tide turned. These most recent observations bear this out, with mode- 2 waves being released daily and passing over the ridge crest a few hours after the tide turned westward. The mode speeds at stations $\mathrm{AC}$ and $\mathrm{AW}$, at 1.92 and $0.90 \mathrm{~m} \mathrm{~s}^{-1}$ for mode-1 and mode-2, respectively, were similar to the pilot study. The observed current speeds with maximum order $1.5 \mathrm{~m} \mathrm{~s}^{-1}$ and key parameters such as the steepness parameter $(\varepsilon)$, excursion parameter (s), and internal Froude number (F) were also similar. A new result here is that several local sources seem to be active, and not just the one observed by 

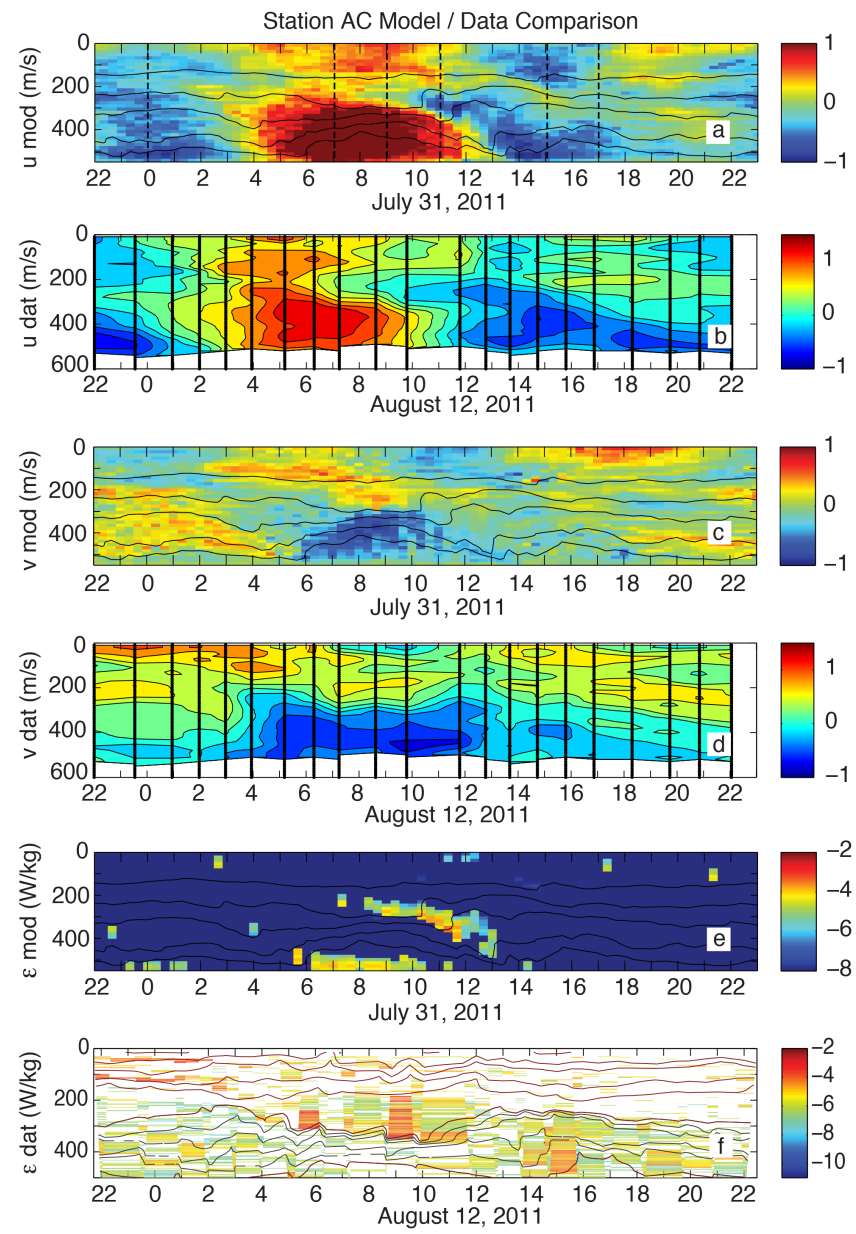

Figure 12. Model/data comparisons between observations at Anchor Station AC and output from the MITgcm model. The model output is from the same location but a fortnight earlier, during the same phase of the tide (see Fig. 1, bottom panel). Shown for comparison are the $u$ component $(\mathbf{a}, \mathbf{b})$; the $v$ component $(\mathbf{c}, \mathbf{d})$; and turbulent dissipation (e, f). The lines on the bottom plot represent density, with a contour interval of 1.0 sigma- $\mathrm{T}$ units (red) and 0.5 sigma-T units (gray). The vertical dotted lines in panel a) represent the times of the model cross-sections shown in Fig. 13. The vertical solid lines in (b) and (d) represent the times of the individual CTD/LADCP casts.

RYRB12. The importance of the observations being atop a prominent sub-ridge should be emphasized: the values used to compute $\varepsilon, s$, and $F$ for the sub-ridge are the "inner" values described by Winters and Armi (2012) and not the much smaller "outer" values in the far field. The local steepness parameter is supercritical to both tides everywhere on the subridge and there is plenty of excursion for lee waves to form.

To better understand the local dynamics, the Massachusetts Institute of Technology general circulation model (MITgcm) was used to compute the flow over the top of the ridge. The MITgcm (Marshall et al., 1997) was used in a three-dimensional configuration similar to Buijsman

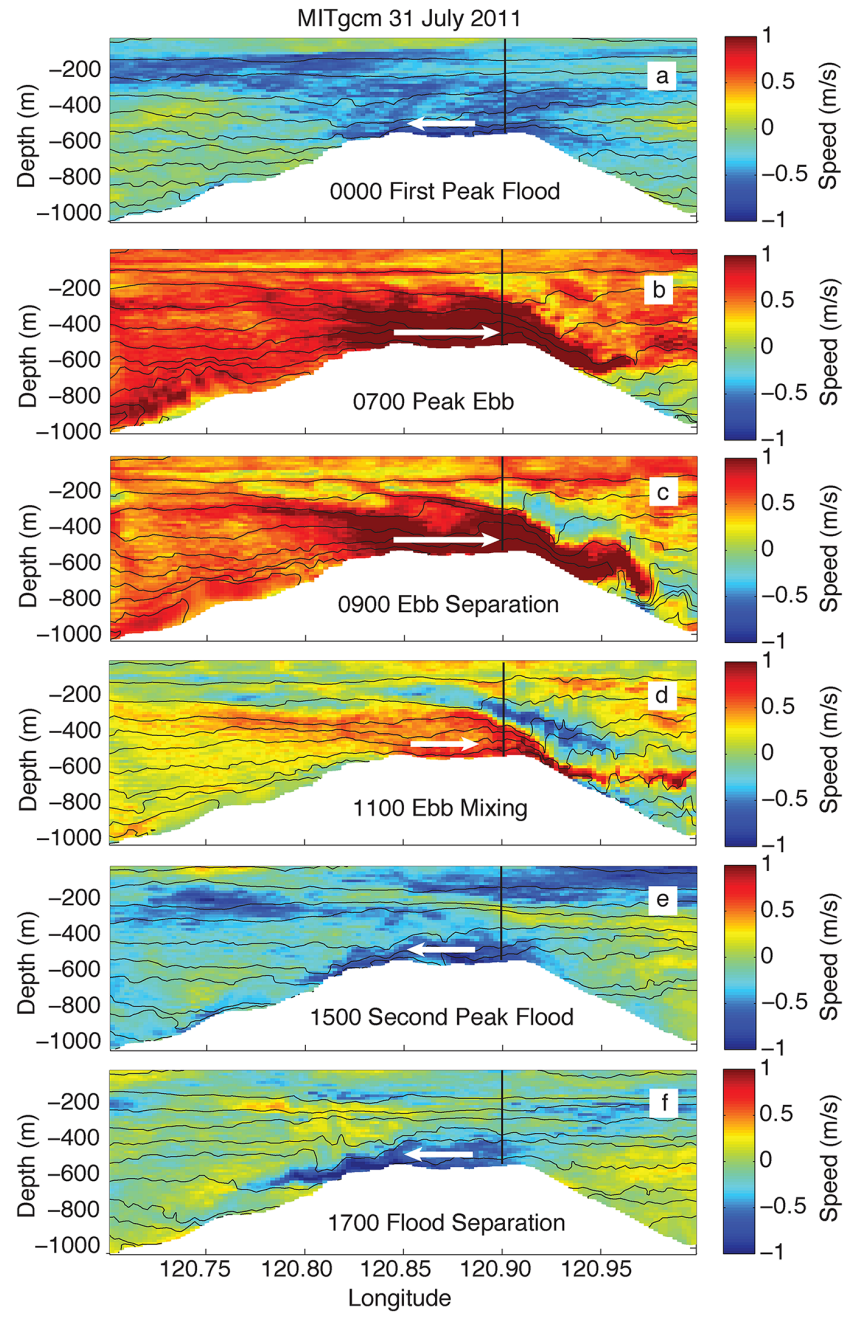

Figure 13. Selected snapshots of the $u$ velocity component (acrossridge) along latitude $21.6^{\circ} \mathrm{N}$ from longitude 120.50 to $121.00^{\circ} \mathrm{E}$. Sections were chosen to illustrate phenomena and the time difference between sections is not constant. The velocities are output from the MITgcm model computed as described in the text. The thin gray lines are isopycnals. The vertical black line is the location of anchor station AC, where the model time series for the same day is presented in Fig. 12a. White arrows indicate the direction and relative magnitude of the tide across the top of the ridge.

et al. (2014), but with a higher resolution. The model domain was $1120 \times 992$ grid cells in the east-west and northsouth directions, respectively, which translates to about $1425 \times 675 \mathrm{~km}$. The domain was centered at the two ridges in the Luzon Strait. The horizontal resolution was maximal near the center of the domain $(250 \times 250 \mathrm{~m})$, decreasing to $15 \times 15 \mathrm{~km}$ near the model boundaries. The model has 154 vertical layers with a resolution of $15 \mathrm{~m}$ in the top $2000 \mathrm{~m}$ stretched to $200 \mathrm{~m}$ at $2800 \mathrm{~m}$ depth and increasing to $271 \mathrm{~m}$ at $6000 \mathrm{~m}$ depth.

The model features a sub-grid-scale mixing scheme that computes vertical viscosities and diffusivities above back- 
ground values of $10^{-5} \mathrm{~m}^{2} \mathrm{~s}^{-1}$ by Thorpe-sorting unstable density profiles (Klymak and Legg, 2010). This scheme has been shown to more accurately predict dissipation rates than shear-driven schemes in two-dimensional hydrostatic model simulations (Klymak and Legg, 2010; Buijsman et al., 2012). The simulations were therefore run in hydrostatic mode. The horizontal viscosity and diffusivity were $10^{-2} \mathrm{~m}^{2} \mathrm{~s}^{-1}$ and $10^{-4} \mathrm{~m}^{2} \mathrm{~s}^{-1}$ and were held constant in time. The quadratic bottom drag was set to 0.0025 .

The boundary forcing and stratification were similar to Buijsman et al. (2014). The topographic data base was created by merging gridded multi-beam data collected at sea with a resolution of order $300 \mathrm{~m}$ with SRTM30 PLUS data from the Smith and Sandwell database with a resolution of order $1 \mathrm{~km}$ (Smith and Sandwell, 1997). The density stratification was derived from temperature and salinity data collected in between the ridges (Alford et al., 2011). The stratification is uniform in $(x, y)$ and is a linear function of temperature in $(z)$. The tidal forcing at the eastern, western, northern, and southern model boundaries comprises 10-day time series of zonal and meridional barotropic velocities constructed from amplitudes and phases of eight tidal frequencies. The amplitudes and phases were extracted from the TPXO7.2 tidal inversion model (Egbert et al., 1994) at the location of the model boundaries. To allow for the inward propagation of the barotropic tidal waves while damping the outward propagating baroclinic waves, the interior velocity fields were nudged to the barotropic tidal velocities over 12 cells in from the boundaries. The interior temperature was also nudged to a time-invariant temperature profile at the boundaries.

For the purpose of comparing the model results with the observational results presented here, a section along $21.6^{\circ} \mathrm{N}$ from 120.5 to $121.0^{\circ} \mathrm{E}$ was extracted from the model output. The section spans all three time series stations in space (Fig. 1b, c) but since the model was only run from 25 July to 4 August 2011, it does not overlap in time. Since the observed regime was primarily tidal, the approach here is to compare the time series from station data with model output from a similar position in the previous fortnightly envelope (Fig. 1d). That is, the data from stations AC and AW collected on 12 and 14 August were compared with the model results $\left(\mathrm{C}^{\prime}\right.$ and $\mathrm{W}^{\prime}$ in Fig. 1d) from 31 July and 2 August, respectively. Once the veracity of the model has been established, it can then be used to compute the terms in the energy equation and further illuminate the forcing and dynamics. The results for station AC (Fig. 12) show that the model simulated the tidal features well. The main features such as the bottom-trapped southeastward tidal surge appeared about an hour later than the observations, owing to a slightly later peak of the barotropic tide on 31 July (06:00) relative to 12 August (05:00). The mid-depth minimum in the $u$ component and flow reversal near $300 \mathrm{~m}$ depth in the $v$ component appeared in both model and observations (Fig. 12a-d). The westward surge moving up over the top of the eastward surge during 06:00-12:00 in the $u$ component also appeared in both model and observations (Fig. 12a, b). This westward surge elevated the isopycnals during 10:00-14:00 in the model and during 12:00-16:00 in the observations (compare Fig. 12a or $\mathrm{c}$ with 12f). The dissipation computed from the model and observations were similar in magnitude but different in location: high dissipation in the model occurred primarily in the high shear zones above and beneath the southeastward tidal bore between 06:00 and 13:00 (Fig. 12e). In the observations, the highest dissipation was associated with overturns in the core of the mode-2 wave (at 09:00) and the upslope westward tidal bore (at 15:00) (Fig. 12f). This figure indicates that the model performed well for simulating the highly nonlinear tidal features but may not fully resolve the higher-frequency nonlinear internal waves.

A time series of cross sections along $21.6^{\circ} \mathrm{N}$ shows the temporal evolution of the tidal currents and density structure over the entire ridge from the MITgcm (Fig. 13). The strong asymmetry in the tide is immediately apparent: the eastward surge (red, Fig. 13b, c, d) was stronger and extended higher up into the water column than the westward surge (blue, Fig. 13a, e, f). The ebb surge lifts denser water from the western side up and over the top of the ridge. As the ebb surge plunged down along the eastern slope, it separated from the bottom when it reached ambient density and was surrounded by westward-moving water both above and below (Fig. 13c). High dissipation (not shown) occurred in these high vertical shear zones. The isopycnals near the nose of the plume were vertical at this time accompanied by overturns and intense mixing in the model. By $4 \mathrm{~h}$ after peak ebb tide at 11:00 (Fig. 13d), substantial mixing had occurred which eroded the eastward plume, now centered near $700 \mathrm{~m}$ depth, and the westward flow above and below had accelerated. The mode- 2 waves eventually emerged from this westward-moving core (blue) centered near $200 \mathrm{~m}$ over the top of the ridge. Note that the stratification there was also favorable to mode- 2 waves with a minimum in the vertical density gradient near $200 \mathrm{~m}$ and much stronger stratification below. This was likewise true in the observations (Fig. 12f). Large overturns continued to occur in the region centered near $120.95^{\circ}$ E. Note that in the model the westward bottom surge on the flood tide also separated from the bottom near $120.80^{\circ} \mathrm{E}$ with associated strong shear (Fig. 13f). This suggests the possibility of eastward-propagating high-frequency internal waves being released on the turn of the flood tide, but this was not seen in any of the observations. This was because the westward tide, which peaked at $-65 \mathrm{~cm} \mathrm{~s}^{-1}$ in both model and observations, was too weak to arrest the mode- 2 waves.

The model was also quite helpful in discerning the spatial distribution of the energy flux divergence. Everywhere east of $120.95^{\circ} \mathrm{E}$, the zonal energy flux was eastward, likely associated with the northeastward-flowing Kuroshio Current. Over the ridge top, the zonal flux was always westward, decreasing almost linearly from $-2.4 \times 10^{4} \mathrm{~W} \mathrm{~m}^{-1}$ at $120.925^{\circ} \mathrm{E}$ to zero at $120.85^{\circ} \mathrm{E}$. The model fluxes at $\mathrm{AC}$ and 
$\mathrm{AW}$, at -1.14 and $+0.23 \times 10^{4} \mathrm{~W} \mathrm{~m}^{-1}$, respectively, were smaller than the observed fluxes, likely due to the model being forced by weaker velocities in the far field. The flux divergence, however, was nearly equal in the model and observations, with 1.8 vs. $2.0 \mathrm{~W} \mathrm{~m}^{-2}$ for the model and observations, respectively. This gives added confidence that the terms in the energy balance computed from the observations using Eq. (1) are the correct order of magnitude and that the environment over the shallow regions of the northern HengChun Ridge was highly dissipative.

\section{Conclusions}

Two research cruises were conducted from R/V OCEAN RESEARCHER 3 during 5-16 August 2011 to study the generation of high-frequency nonlinear internal waves (NLIW) over the northern Heng-Chun Ridge south of Taiwan. The primary study site, centered near $21^{\circ} 34^{\prime} \mathrm{N}, 120^{\circ} 54^{\prime} \mathrm{E}$, was on top of a sub-ridge about $15 \mathrm{~km}$ wide by $400 \mathrm{~m}$ high atop the primary ridge, with a sill depth of approximately $600 \mathrm{~m}$. The bottom slope was steep over both sides of the ridge, supercritical with respect to both diurnal and semidiurnal tides. A mooring to record temperature, salinity, and velocity was also deployed on top of the $\mathrm{HC}$ ridge at $21^{\circ} 34.1^{\prime} \mathrm{N}, 120^{\circ} 52.7^{\prime} \mathrm{E}$, $609 \mathrm{~m}$ depth, from 8 to 15 August 2011. Time series were collected using a shipboard LADCP/CTD package at three additional sites while the mooring was in place, on $12 \mathrm{Au}$ gust (AC), 13 August (AE), and 14 August (AW). Underway data were collected throughout the cruise using the ship's ADCP, EK500 echo sounder, and digitally recording surface radar. Two underway CTD (UCTD) transects were also collected.

The key result of the cruise is that a profusion of mode2 NLIWs, but no mode-1 NLIWs, was observed by all the sensors. The high-frequency waves were aliased by some sensors (CTD, UCTD) and appeared as a wide "bulge" in the thermal structure, but comparison with faster concurrent sensors such as the mooring, echo sounder and surface radar show unequivocally that these bulges were composed of high-frequency internal waves. Some of the waves were solitary, while others had as many as seven evenly spaced waves per packet. The waves all exhibited classic mode- 2 velocity structure with westward velocity cores centered between 150 and $200 \mathrm{~m}$ depth and opposing eastward velocities in the layers above and below. The waves propagated slowly $\left(0.29-0.69 \mathrm{~m} \mathrm{~s}^{-1}\right)$ in the direction of the middle layer velocity, which was WNW or WSW depending on the wave. This observed speed was slower than the computed mode- 2 speed under the ambient stratification $\left(90 \mathrm{~cm} \mathrm{~s}^{-1}\right)$, and was likely due to the waves being opposed by the eastward bottomtrapped tide. The orbital velocities in the waves exceeded $80 \mathrm{~cm} \mathrm{~s}^{-1}$ and produced stunning surface features such as slicks and breaking waves that were observed in the divergent and convergent regions just before and after the crests of the waves. At least two and possibly three most common propagation directions and arrival times emerged from the analysis, suggesting multiple generation sites near the ridge. The wave crests were only order $10 \mathrm{~km}$ long, suggesting confinement by the channel dimensions across the top of the sill.

The total energy, energy fluxes, and flux divergence were computed for the $24 \mathrm{~h}$ time series collected at stations AC and AW where mode- 2 waves were observed. There was about $960 \mathrm{MJ} \mathrm{m}^{-1}$ of pseudo-energy (KE + PE) at AC vs. $420 \mathrm{MJ} \mathrm{m}^{-1}$ at $\mathrm{AW}$. The energy at $\mathrm{AW}$ was approximately equipartitioned, with KE slightly exceeding $\mathrm{PE}$ with a ratio of 1.2. At station AC however the KE / PE ratio was 2.2 which was not in agreement with linear or weakly nonlinear theory. The energy at AC was about half that of a large SCS transbasin wave, but also represents the energy in an entire packet of mode- 2 waves and not just the lead wave. Thus, transbasin waves are significantly larger and more energetic. The Heng-Chun mode- 2 waves near the source however were more energetic than all other observations including those on continental shelves. The vertically integrated energy flux due to the waves was westward atop the ridge and equal to $-4.5 \times 10^{4} \mathrm{~W} \mathrm{~m}^{-1}$ at station $\mathrm{AC}$ and $-3.0 \times 10^{4} \mathrm{~W} \mathrm{~m}^{-1}$ at station AW. Assuming that the tides were regular and there wasn't too much difference between August 12 and 14, this leads to a flux divergence of $2.0 \mathrm{~W} \mathrm{~m}^{-2}$. Model results computed using the MITgcm produced a flux divergence of $1.8 \mathrm{~W} \mathrm{~m}^{-2}$ on 31 July when the tidal phase was about the same as 12 August.

Turbulent dissipation, as computed using Thorpe scaling methods, was very high on and around this subridge atop the primary Heng-Chun Ridge. This was not surprising since roll-ups, Kelvin-Helmholz billows, and other shear phenomena were easily visible in the acoustic backscatter data. The largest overturns computed from the anchor station data were $140 \mathrm{~m}$ tall in the core of the mode- 2 wave and $120 \mathrm{~m}$ near the bottom inside the westward upslope tidal surge. The associated turbulent dissipation of order $10^{-4}-10^{-3} \mathrm{~W} \mathrm{~kg}^{-1}$ was slightly higher than deeper portions of the Heng-Chun Ridge $\left(10^{-5} \mathrm{~W} \mathrm{~kg}^{-1}\right)$ (Alford et al., 2011). This represents greater dissipation than all other previous observations except those east of the Lan-Yu ridge between the Batan and Itabayat islands, where the dissipation reached $10^{-2} \mathrm{~W} \mathrm{~kg}^{-1}$ (Pinkel et al., 2012). This, combined with the MITgcm results, suggests that breaking lee waves were likely the source of this high turbulence near the bottom, which was subsequently advected back up over the ridge on the turn of the tide. The high dissipation could account for $72 \%$ of the energy loss between stations AC and AW on top of the ridge, and suggests that all the energy in the mode- 2 waves could be dissipated in only $8.9 \mathrm{~h}$. This suggests, consistent with earlier work, that higher-mode internal waves are highly dissipative and do not propagate great distances from the source. This generation site atop the northern ridge likely does not make a large contribution to the energy of the large transbasin waves 
that propagate all the way across the northern South China Sea.

The average value for the tidal conversion between stations $\mathrm{AC}$ and $\mathrm{AW}$ was $2.8 \mathrm{~W} \mathrm{~m}^{-2}$. The leads to an energy equation in which the conversion is nearly balanced by the energy flux divergence and the turbulent dissipation. The numbers are within the range of $1-3 \mathrm{~W} \mathrm{~m}^{-2}$ found by other investigators on other parts of the Heng-Chun Ridge (Alford et al., 2011). This provides some confidence that the essential balance has been captured even though the nonlinear and nonhydrostatic terms in the energy equation could not be estimated with the data in hand. The high value of $q=0.59$, the ratio of the turbulent dissipation to the conversion, reinforces the idea that the environment is highly dissipative over the northern Heng-Chun Ridge.

The details of the wave generation process remain elusive. The results are consistent with Ramp et al. (2012) that the mode- 2 waves are the lowest mode that can be arrested by the prevailing tidal currents. The MITgcm sections suggest that a thin band of westward velocity moves up and over the plunging eastward bottom-trapped tidal plume, and into a region of minimum stratification near $200 \mathrm{~m}$ depth. The high-frequency waves seem to emerge from this region. The Kuroshio Current, carrying a thermostad near $17^{\circ} \mathrm{C}$ and a salinity maximum of 34.5 near the same depth, contributes to an ambient stratification which is conducive to mode-2 wave formation. This is a three-dimensional process as the timing and directions of the waves observed suggest at least three sources on the eastern flank of the ridge. Additional observations with more specialized instrumentation would be necessary to positively identify the generation regions.

Acknowledgements. This work was supported as part of the ONR Internal Waves in Straits (IWISE) experiment under grant number N00014-12-1-0371 and by the National Science Council (NSC) of Taiwan. The cruises were expertly executed by the officers, crew, and professional staff of the research vessel OCEAN RESEARCHER 3. An anonymous review and helpful comments by J. Moum (OSU) improved the quality of the manuscript.

Edited by: V. I. Vlasenko

Reviewed by: one anonymous referee

\section{References}

Alford, M. H., Lien, R.-C., Simmons, H., Klymak, J., Ramp, S. R., Yang, Y.-J., Tang, T.-Y., Farmer, D., and Chang, M.-H.: Speed and evolution of nonlinear internal waves transiting the South China Sea, J. Phys. Oceanogr., 40, 1338-1355, 2010.

Alford, M. H., MacKinnon, J. A., Nash, J. D., Simmons, H., Pickering, A., Klymak, J. M., Pinkel, R., Sun, O., Rainville, L., Musgrave, R., Beitzel, T., Fu, K.-H., and Lu, C.-W.: Energy flux and Dissipation in Luzon Strait: Two tales of two ridges, J. Phys. Oceanogr. 41, 2211-2222, 2011.
Apel, J. R., Holbrook, J. R., Tsai, J., and Liu, A. K.: The Sulu Sea internal soliton experiment, J. Phys. Oceanogr., 15, 1625-1651, 1985.

Buijsman, M. C., Kanarska, Y., and McWilliams, J. C.: On the generation and evolution of nonlinear internal waves in the South China Sea, J. Geophys. Res.-Oceans, 115, C02012, doi:10.1029/2009JC005275, 2010a.

Buijsman, M. C., McWilliams, J. C., and Jackson, C. R.: East-west asymmetry in nonlinear internal waves from Luzon Strait, J. Geophys. Res.-Oceans, 115, C1057, doi:10.1029/2009JC006004, 2010b.

Buijsman, M. C., Legg, S., and Klymak, J.: Double-ridge internal tide interference and its effect on dissipation in Luzon Strait, J. Phys. Oceanogr., 42, 1337-1356. 2012.

Buijsman, M. C., Klymak, J. M., Legg, S., Alford, M. H., Farmer, D., MacKinnon, J. A., Nash, J. D., Park, J. H., Pickering, A., and Simmons, H.: Three Dimensional Double Ridge Internal Tide Resonance in Luzon Strait, J. Phys. Oceanogr., 44, 850-869, 2014.

Dillon, T. M.: Vertical overturns: A comparison of Thorpe and Ozmidov length scales, J. Geophys. Res., 87, 9601-9613, 1982.

Duda, T. F., Lynch, J. F., Irish, J. D., Beardsley, R. C., Ramp, S. R., Chiu, C.-S., Tang, T.-Y., and Yang, Y.-J.: Internal tide and nonlinear internal wave behavior at the continental slope in the northern South China Sea, IEEE/J. Oc. Eng., 29, 1105-1131, 2004.

Duda, T. F., Newhall, A. E., Gawarkiewicz, G., Caruso, M. J., Graber, H. C., Yang, Y. J., and Jan, S.: Significant internal waves and internal tides measured northeast of Taiwan, J. Mar. Res., 71, 47-81, 2013.

Egbert, G. and Erofeeva, S.: Efficient inverse modeling of barotropic ocean tides, J. Atmos. Oceanic Technol., 19, 183-204, 2002.

Egbert, G., Bennett, A., and Foreman, M.: TOPEX/Poseidon tides estimated using a global inverse model, J. Geophys. Res., 99, 24821-24852, 1994.

Farmer, D. M. and Smith, J. D.: Tidal interaction of stratified flow with a sill in Knight Inlet, Deep-Sea Res. A, 27, 239-254, 1980.

Farmer, D., Li, Q., and Park, J.-H.: Internal wave observations in the South China Sea: The role of rotation and non-linearity, Atmos. Ocean, 47, 267-280, 2009.

Garrett, C. and Kunze, E.: Internal tide generation in the deep ocean, Ann. Rev. Fluid Mech., 39, 57-87, 2007.

Jan, S., Lien, R.-C., and Ting, C.-H.: Numerical study of baroclinic tides in Luzon Strait, J. Oceanogr., 64, 789-802, 2008.

Kang, D. and Fringer, O.: Energetics of barotropic and baroclinic tides in the Monterey Bay area, J. Phys. Oceanogr., 42, 272-290, 2012.

Klymak, J. M. and Legg, S.: A simple mixing scheme for models that resolve breaking internal waves, Ocean Modell., 33, 224234, 2010.

Klymak, J. M., Pinkel, R., Liu, C.-T., Liu, A. K., and David, L.: Prototypical solitons in the South China Sea, Geophys. Res. Lett., 33, L11607, doi:10.1029/2006GL025932, 2006.

Klymak, J. M., Legg, S., and Pinkel, R.: A simple parameterization of turbulent tidal mixing near supercritical topography, J. Phys. Oceanogr., 40, 2059-2074, doi:10.1175/2010JPO4396.1, 2010.

Klymak, J. M., Alford, M. H., Pinkel, R., Lien, R. C., and Yang, Y. J.: The breaking and scattering of the internal tide on a continental slope, J. Phys. Oceanogr., 41, 926-945, 2011. 
Klymak, J. M., Legg, S., Alford, M. H., Buijsman, M., Pinkel, R., and Nash, J. D.: The direct breaking of internal waves at steep topography, Oceanography, 25, 150-159, 2012.

Kunze, E., Rosenfeld, L. K., Carter, G. S., and Gregg, M. C.: Internal waves in the Monterey Submarine Canyon, J. Phys. Oceanogr., 32, 1890-1913, 2002.

Lai, Z., Chen, C., Cowles, G. W., and Beardsley, R. C.: A nonhydrostatic version of FVCOM: 2. Mechanistic study of tidally generated nonlinear internal waves in Massachusetts Bay, J. Geophys. Res.-Oceans, 115, doi:10.1029/2010JC006331, 2010.

Lamb, K. G. and Nguyen, V. T.: Calculating energy flux in internal solitary waves with an application to reflectance, J. Phys. Oceanogr., 39, 559-580, 2009.

Lee, C. Y. and Beardsley, R. C.: The generation of long nonlinear internal waves in weakly stratified shear flows, J. Geophys. Res., 79, 453-462, doi:10.1029/JC079i003p00453, 1974.

Lee, C. M, Kunze, E., Sanford, T. B., Nash, J. D., Merrifield, M. A., and Holloway, P. E.: Internal tides and turbulence along the 3000-m isobath of the Hawaiian Ridge, J. Phys. Oceanogr., 36, 1165-1183, 2006.

Legg, S. and Klymak, J. M.: Internal hydraulic jumps and overturning generated by tidal flow over a tall steep ridge, J. Phys. Oceanogr., 38, 1949-1964, doi:10.1175/2008JPO3777.1, 2008.

Li, Q. and Farmer, D. M.: The generation and evolution of nonlinear internal waves in the deep basin of the South China Sea, J. Phys. Oceanogr., 41, 1345-1363, 2011.

Lien, R. C., Tang, T. Y., Chang, M. H., and D'Asaro, E. A.: Energy of nonlinear internal waves in the South China Sea, Geophys. Res. Lett., 32, L05615, doi:10.1029/2004GL022012, 2005.

Liu, A. K., Ramp, S. R., Zhao, Y., and Tang, T.-Y.: A Case Study of Internal Wave Propagation During ASIAEX-2001, IEEE/J. Oc. Eng., 29, 1144-1156, 2004.

Liu, A. K., Chang, Y. S., Hsu, M. K., and Liang, N. K.: Evolution of nonlinear internal waves in the East and South China Seas, J. Geophys. Res., 103, 7995-8008, 1998.

Marshall, J., Adcroft, A., Hill, C., Perelman, L., and Heisey, C.: A finite-volume, incompressible Navier-Stokes model for studies of the ocean on parallel computers, J. Geophys. Res., 102, 57535766, doi:10.1029/96JC02775, 1997.

Maxworthy, T.: A note on the internal solitary waves produced by tidal flow over a three-dimensional ridge, J. Geophys. Res.Oceans, 84, 338-346, 1979.

Moum, J. N., Klymak, J. M., Nash, J. D., Perlin, A., and Smyth, W. D.: Energy transport in nonlinear internal waves, J. Phys. Oceanogr., 37, 1968-1988, 2007.

Nash, J. D., Alford, M. H., and Kunze, E.: Estimating internal wave energy fluxes in the ocean, J. Atmos Ocean. Tech., 22, 15511570, 2005.

Nash, J. D., Kunze, E., Lee, C. M., and Sanford, T. B.: Structure of the baroclinic tide generated at Kaena Ridge, Hawaii, J. Phys. Oceanogr., 36, 1123-1135, 2006.

Nash, J., Alford, M., Kunze, E., Martini, K., and Kelley, S.: Hotspots of deep ocean mixing on the Oregon continental slope, Geophys. Res. Lett., 34, L010605, doi:10.1029/2006GL028170, 2007.

Osborn, T. R.: Estimates of the local rate of vertical diffusion from dissipation measurements, J. Phys. Oceanogr. 10, 83-89, 1980.
Pinkel, R., Buijsman, M., and Klymak, J. M.: Breaking topographic lee waves in a tidal channel in Luzon Strait, Oceanography, 25, 160-165, 2012.

Rainville, L. and Pinkel, R.: Observations of energetic highwavenumber internal waves in the Kuroshio, J. Phys. Oceanogr., 34, 1495-1505, 2004.

Ramp, S. R., Chiu, C. S., Kim, H.-R., Bahr, F. L., Tang, T.-Y., Yang, Y. J., Duda, T., and Liu, A. K.: Solitons in the Northeastern South China Sea Part I: Sources and Propagation Through Deep Water, IEEE/J. Ocean. Eng., 29, 1157-1181, 2004.

Ramp, S. R., Yang, Y. J., and Bahr, F. L.: Characterizing the nonlinear internal wave climate in the northeastern South China Sea, Nonlin. Processes Geophys., 17, 481-498, doi:10.5194/npg-17481-2010, 2010.

Ramp, S. R., Yang, Y. J., Reeder, D. B., and Bahr, F. L.: Observations of a mode-2 nonlinear internal wave on the northern HengChun Ridge south of Taiwan, J. Geophys. Res., 117, C03043, doi:10.1029/2011JC007662, 2012.

Rudnick, D. L. and Klinke, J.: The Underway ConductivityTemperature-Depth Instrument, J. Atmos. Ocean. Technol., 24, 1910-1923, 2007.

Scotti, A., Beardsley, R. C., and Butman, B.: Generation and propagation of nonlinear internal waves in Massachusetts Bay, J. Geophys. Res., 112, C10001, doi:10.1029/2007JC004313, 2007.

Shroyer, E. L., Moum, J. N., and Nash, J. D.: Mode 2 waves on the continental shelf: Ephemeral components of the nonlinear internal wavefield, J. Geophys. Res.-Oceans, 115, C07001, doi:10.1029/2009JC005605, 2010.

Smith, W. H. F. and Sandwell, D. T.: Global seafloor topography from satellite altimetry and ship depth soundings, Science, 277, 1957-1962, 1997.

Thorpe, S. A.: Turbulence and mixing in a Scottish loch, Phil. Trans. Roy. Soc. Ldn. A., 286, 125-181, 1977.

Thurnherr, A. M.: A practical assessment of the errors associated with full-depth LADCP profiles obtained using Teledyne RDI Workhorse acoustic Doppler current profilers, J. Atmos. Ocean. Technol., 27, 1215-1227, 2010.

Visbeck, M.: Deep velocity profiling using lowered acoustic Doppler current profilers: Bottom track and inverse solutions, J. Atmos. Ocean. Technol., 19, 794-807, 2002.

Vlasenko, V., Stashchuk, N., Guo, C., and Chen, X.: Multimodal structure of baroclinic tides in the South China Sea, Nonlin. Processes Geophys., 17, 529-543, doi:10.5194/npg-17-529-2010, 2010.

Winters, K. B. and Armi, L.: The response of a continuously stratified fluid to an oscillating flow past an obstacle, J. Fluid Mech., 727, 83-118, 2013.

Yang, Y.-J., Tang, T. Y., Chang, M. H., Liu, A. K., Hsu, M.-K., and Ramp, S. R.: Solitons northeast of Tung-Sha Island during the ASIEAX pilot studies, IEEE J. Ocean. Eng., 29, 1182-1199, 2004.

Yang, Y. J., Fang, Y. C., Chang, M.-H., Ramp, S. R., Kao, C.C., and Tang, T.-Y.: Observations of second baroclinic mode internal solitary waves on the continental slope of the northern South China Sea, J. Geophys. Res.-Oceans, 114, C10003, doi:10.1029/2009JC005318, 2009. 
Yang, Y. J., Fang, Y. C., Chang, Y.-T., Tang, T. Y., and Ramp, S. R.: Convex and concave types of second baroclinic mode internal solitary waves, Nonlin. Processes Geophys., 17, 605-614, doi:10.5194/npg-17-605-2010, 2010.
Zhang, Z., Fringer, O. B., and Ramp, S. R.: Three-dimensional, nonhydrostatic numerical simulation of nonlinear internal wave generation and propagation in the South China Sea, J. Geophys. Res.-Oceans, 116, C05022, doi:10.1029/2010JC006424, 2011. 